\title{
Postcranial anatomy and histology of Seymouria, and the terrestriality of seymouriamorphs
}

\author{
Kayla D Bazzana ${ }^{\text {Corresp., } 1,2}$, Bryan M Gee ${ }^{1}$, Joseph J Bevitt ${ }^{3}$, Robert R Reisz ${ }^{1,4}$ \\ 1 Department of Biology, University of Toronto Mississauga, Mississauga, Ontario, Canada \\ 2 Department of Natural History, Royal Ontario Museum, Toronto, Ontario, Canada \\ 3 Australian Centre for Neutron Scattering, Australian Nuclear Science and Technology Organisation, Lucas Heights, New South Whales, Australia \\ 4 International Center of Future Science, Dinosaur Evolution Research Center, Jilin University, Changchun, Jilin Province, China \\ Corresponding Author: Kayla D Bazzana \\ Email address: kayla.bazzana@mail.utoronto.ca
}

Seymouria is the best known of the seymouriamorphs, a group of Permo-Carboniferous reptiliomorphs with both terrestrial and aquatic taxa. The majority of research on Seymouria has focused on cranial anatomy, with few detailed descriptions or illustrations of the postcrania. We utilized neutron computed tomography ( $\mathrm{nCT}$ ) and histological sampling to provide updated, detailed illustrations that clarify details of the postcranial anatomy and to assess the development and histology of Seymouria through specimens from the early Permian Richards Spur locality. The correlation of morphological and histological data indicate rapid metamorphosis in this terrestrially capable stem amniote, with the youngest specimen being postmetamorphic despite being distinctly younger than premetamorphic individuals of Discosauriscus, the only other seymouriamorph to have been histologically sampled. The microanatomical data (e.g. semi-open medullary cavity) also substantiates the hypothesis that Seymouria was terrestrial based on interpretation of external features, although the persistence of a modestly developed medullary spongiosa in comparison to either Discosauriscus or to other co-occurring terrestrial tetrapods suggests additional nuances that require further exploration. In the absence of clearly recognizable postmetamorphic stages in several seymouriamorph taxa, it is difficult to determine the evolutionary trajectory of terrestriality within the clade. Our analysis provides the first histological characterization of the life history of Seymouria and highlights the need for further study of seymouriamorph ontogeny. 
1 Postcranial anatomy and histology of Seymouria, and the terrestriality of seymouriamorphs 2

3

4 Kayla D. Bazzana ${ }^{1,2}$; Bryan M. Gee ${ }^{1}$; Joseph J. Bevitt ${ }^{3}$; Robert R. Reisz ${ }^{1,4}$

5

$6 \quad{ }^{1}$ Department of Biology, University of Toronto Mississauga, Mississauga, ON, Canada

$7 \quad 2$ Department of Natural History, Royal Ontario Museum, Toronto, ON, Canada

$8 \quad{ }^{3}$ Australian Centre for Neutron Scattering, Australian Nuclear Science and Technology

9 Organisation, Lucas Heights, NSW, Australia

$10{ }^{4}$ International Center of Future Science, Dinosaur Evolution Research Center, Jilin University,

11 Changchun, Jilin Province, China

12

13 Corresponding Author:

14 Kayla Bazzana

15 Department of Biology, William G. Davis Building, University of Toronto Mississauga, 3359

16 Mississauga Rd., Mississauga, ON, L5L 1C6, Canada

17 Email address: kayla.bazzana@mail.utoronto.ca 


\section{Abstract}

Seymouria is the best known of the seymouriamorphs, a group of Permo-Carboniferous reptiliomorphs with both terrestrial and aquatic taxa. The majority of research on Seymouria has

21 focused on cranial anatomy, with few detailed descriptions or illustrations of the postcrania. We

22 utilized neutron computed tomography (nCT) and histological sampling to provide updated, 23 detailed illustrations that clarify details of the postcranial anatomy and to assess the development 24 and histology of Seymouria through specimens from the early Permian Richards Spur locality.

25 The correlation of morphological and histological data indicate rapid metamorphosis in this terrestrially capable stem amniote, with the youngest specimen being postmetamorphic despite being distinctly younger than premetamorphic individuals of Discosauriscus, the only other seymouriamorph to have been histologically sampled. The microanatomical data (e.g. semi-open medullary cavity) also substantiates the hypothesis that Seymouria was terrestrial based on interpretation of external features, although the persistence of a modestly developed medullary spongiosa in comparison to either Discosauriscus or to other co-occurring terrestrial tetrapods suggests additional nuances that require further exploration. In the absence of clearly recognizable postmetamorphic stages in several seymouriamorph taxa, it is difficult to determine the evolutionary trajectory of terrestriality within the clade. Our analysis provides the first histological characterization of the life history of Seymouria and highlights the need for further study of seymouriamorph ontogeny. 


\section{Introduction}

Seymouriamorphs are among the best-known stem amniotes (but see Marjanović \&

41 Laurin, 2019 for alternative phylogenetic placement) and are known primarily from Lower

42 Permian deposits in North America, Europe, and Russia (Broili, 1904; Amalitzky, 1921; White,

43 1939; Vaughn, 1966; Berman, Reisz, \& Eberth, 1987; Berman \& Martens, 1993; Sullivan \&

44 Reisz, 1999; Bulanov, 2014). Within seymouriamorphs, only the monotypic family

45 Seymouriidae is known from both North America and Eurasia (Broili, 1904; White, 1939;

46 Vaughn, 1966; Berman \& Martens, 1993). Of the North American localities, the materials of

47 Seymouria with the greatest detail of preservation are known from the Dolese Brothers

48 Limestone quarry near Richards Spur, Oklahoma (Sullivan \& Reisz, 1999; Bazzana et al., 2020).

49 However, the only previously described postcranial material from this locality consists of a few

50 isolated elements (Sullivan \& Reisz, 1999). Furthermore, the most detailed description and

51 figuring of the postcrania of Seymouria from any locality is that completed by White (1939).

52 Subsequent authors have provided focused descriptions of the atlas-axis complex (Berman,

53 Reisz, \& Eberth 1987; Sumida, Lombard, \& Berman, 1992) and the manus and pes (Berman et

54 al., 2000), but White's (1939) work remains the most thorough description of the postcranial

55 skeleton in its entirety. While the interpretations made by White (1939) have been largely

56 supported, or at least not overturned, by subsequent authors, his illustrations were unlabelled,

57 somewhat stylized, and from slightly angled, non-standard perspectives, which collectively

58 limits their utility. As stem amniotes that are well-documented in the fossil record,

59 seymouriamorphs provide a relatively accessible window through which to examine

60 morphological changes associated with terrestrial lifestyles in Paleozoic tetrapods, and updated

61 osteology of the postcranial skeleton with detailed figures and descriptions that can be readily

62 utilized by other workers is of great import.

Peer] reviewing PDF | (2019:10:42003:2:0:NEW 30 Jan 2020) 
Spur locality, including several articulated vertebrae and a complete humerus, femora, and

fibula, and provide updated descriptions, illustrations, and images of the postcrania. Analysis of several limb elements and vertebrae using neutron computed tomography (nCT) and histological sampling provides important details regarding the development and internal anatomy of the postcrania of Seymouria and contributes to our understanding of the extent to which these stem amniotes were adapted to terrestrial lifestyles.

\section{Materials \& Methods}

Neutron tomography. Neutron tomography measurements were performed at the DINGO thermal-neutron radiography/ tomography/imaging station (Garbe et al., 2015) located at, and tangentially facing, the $20 \mathrm{MW}$ Open-Pool Australian Lightwater (OPAL) reactor housed at the Australian Nuclear Science and Technology Organisation (ANSTO), Lucas Heights, New South Wales, Australia. The DINGO facility utilises a quasi-parallel collimated beam of thermal neutrons.

For the femur (ROMVP 80915) and the fibula (ROMVP 80917), the instrument was equipped with an Iris 15TM Large Field of View sCMOS camera (5056 x 2968 pixel, 16-bit) and Zeiss Ikon $100 \mathrm{~mm} \mathrm{f/2.0} \mathrm{Makro} \mathrm{Planar} \mathrm{lens.} \mathrm{Based} \mathrm{on} \mathrm{a} \mathrm{desired} \mathrm{spatial} \mathrm{resolution} \mathrm{of} \sim 60 \mu \mathrm{m}$ across the partially-embedded femur and fibula, a maximum sample width of $48.5 \mathrm{~mm}$ and minimum sample-to-detector distance of $28 \mathrm{~mm}$, the DINGO instrument was configured with a $30 \mu \mathrm{m}$ thick terbium-doped Gadox scintillator screen (Gd2O2S:Tb, RC Tritec AG) and $25.2 \times$ $25.2 \times 25.2 \mu \mathrm{m}$ voxels for a Field-of-View of $100 \times 74.5 \mathrm{~mm}$.. To maximise counting statistics and minimise subsequent noise in the tomographic reconstruction, a collimation ratio $(L / D)$ of 500 was used, where $L$ is the neutron aperture-to-sample length and $D$ is the neutron aperture 
86 diameter. This high-flux configuration traditionally illuminates a $200 \mathrm{~mm} \times 200 \mathrm{~mm}$ area around

87 the sample area with $4.75 \times 107$ neutrons $\mathrm{cm}-2 \mathrm{~s}-1$, leading to high background radiation and

88 zingers on the detector. A newly installed slit system was implemented to restrict the neutron-

89 irradiated area about the specimen to achieve optimum scan conditions and a divergence-limited

90 spatial resolution of $56 \mu \mathrm{m}$. A total of 900 equally-spaced angle shadow-radiographs were

91 obtained every $0.20^{\circ}$ as the sample was rotated $180^{\circ}$ about its vertical axis. Both dark (closed

92 shutter) and beam profile (open shutter) images were obtained for calibration before initiating

93 shadow-radiograph acquisition. To reduce anomalous noise, a total of three individual

94 radiographs with an exposure length of $4.0 \mathrm{~s}$ were acquired at each angle (Mays, Bevitt, \&

95 Stilwell, 2017) for a total scan time of $4.6 \mathrm{~h}$.

96 For the sacral series (OMNH 79348), a collimation ratio $(L / D)$ of 1000 (Garbe et al.,

97 2015) was used to ensure highest available spatial resolution. The field of view was set to $200 \mathrm{x}$

$98200 \mathrm{~mm}^{2}$ with a voxel size of $73.3 \times 73.3 \times 73.3 \mu \mathrm{m}$ and sample to detector distance of $70 \mathrm{~mm}$.

99 Neutrons were converted to photons with a $100 \mu \mathrm{m}$ thick $\mathrm{ZnS}(\mathrm{Ag}) /{ }^{6} \mathrm{LiF}$ scintillation screen $(\mathrm{RC}$

100 Tritec AG); photons were then detected by an Iris 15 sCMOS camera (16-bit, $5056 \times 2960$

101 pixels) coupled with a Makro Planar $24 \mathrm{~mm}$ Carl Zeiss lens. The tomographic scan consisted of a

102 total of 720 equally-spaced angle shadow-radiographs obtained every $0.25^{\circ}$ as the sample was

103 rotated $180^{\circ}$ about its vertical axis. Both dark (closed shutter) and beam profile (open shutter)

104 images were obtained for calibration before initiating shadow-radiograph acquisition. To reduce

105 anomalous noise, a total of three individual radiographs with an exposure length of $8 \mathrm{~s}$ were

106 acquired at each angle (Mays, Bevitt, \& Stilwell, 2017). These individual radiographs were

107 summed in post-acquisition processing using the Grouped ZProjector function in ImageJ v.1.51h.

108 Total scan time was $5.7 \mathrm{~h}$. 
The individual radiographs were summed in post-acquisition processing using the

110 'Grouped ZProjector' plugin in ImageJ v.1.51h in accordance with our previous measurements;

111 this plugin was developed by Holly (2004). Tomographic reconstruction of the 16-bit raw data

112 was performed using commercially available Octopus Reconstruction v.8.8 software package

113 and the filtered back-projection algorithm to yield virtual slices perpendicular to the rotation

114 axis. When these slices are stacked in a sequence, they form a three-dimensional volume image

115 of the sample. The reconstructed volume data were downsampled by a factor of 2 in ImageJ to

116 reduce computation time, then rendered and segmented with Avizo Lite 9.3.0.

117

118 Histology. Histological preparation followed standard procedures (Padian \& Lamm, 2013). All

119 specimens were photographed prior to embedding in EP4101UV resin (Eager Polymers), which

120 was allowed to cure for 24 hours. ROMVP 80916 (partial femur), ROMVP 81198 (vertebra), and

121 ROMVP 81199 (vertebra) were prepared at the Royal Ontario Museum (ROMVP), Toronto,

122 Canada. Specimens were cut on the IsoMet 1000 precision saw (Buehler) and mounted to frosted

123 plexiglass slides with cyanoacrylate adhesive. For the femora, the cut was made at the

124 approximate region of the minimum diaphyseal circumference; for the vertebra, the first cut was

125 made sagittally (anteroposteriorly) down the midline, and the second cut was made transversely

126 through one of the two halves of the block. For ROMVP 80916 (larger, partial femur), the

127 section is taken slightly proximal to the inferred minimum circumference due to the incomplete

128 specimen's nature.

129 Mounted blocks were trimmed using the IsoMet and ground on the Hillquist Thin

130 Sectioning Machine lapidary wheel. Manual polishing using 1000-mesh grit on glass plates and a

131 combination of $1-\mu \mathrm{m}$ and $5-\mu \mathrm{m}$ grit on polishing cloths was used to remove scratches. ROMVP 
13281200 (partial femur) was prepared in a similar fashion but with a different equipment setup at

133 the University of Toronto Mississauga. Cutting was performed on the Metcut-5 low speed saw

134 (MetLab), initial grinding on the Metcut-10 Geo (MetLab), and manual grinding on a cutlery

135 whetstone block. Imaging was done on two Nikon AZ-100 microscopes, both fitted with a DS-

136 Fil camera and NIS Elements-Basic Research software registered to David C. Evans and to

137 Robert R. Reisz.

138 Preparation of the specimens was performed by Diane Scott and Bryan M. Gee using pin

139 vises and air scribes. Figures were prepared using Adobe Illustrator and Photoshop.

140

\section{Systematic Paleontology}

142 Order Seymouriamorpha Watson, 1917

143 Family Seymouriidae Williston, 1911

144 Genus Seymouria Broili, 1904

145

146 Horizon and locality. Dolese Brothers Limestone Quarry near Richards Spur, Oklahoma, USA.

147 Early Permian (Artinskian).

148

149 Referred specimens. OMNH 74721, right humerus; OMNH 79346, complete vertebra; OMNH

150 79347, string of 11 articulated vertebrae; OMNH 79348, string of three articulated vertebrae;

151 OMNH 79349, complete vertebra; OMNH 79350, partial vertebra; OMNH 79351, complete

152 vertebra; OMNH 79352, partial vertebra; OMNH 79353, partial vertebra; ROMVP 81198,

153 complete vertebra; ROMVP 81199, complete vertebra; ROMVP 80915, left femur; ROMVP

154 80916, proximal left femur; ROMVP 80917, left fibula; ROMVP 81200, distal left femur. 


\section{Anatomical Description}

157 Vertebra. OMNH 79346, OMNH 79349, OMNH 79350, OMNH 79353, ROMVP 81198, and

158 ROMVP 81199 are isolated presacral vertebrae between the tenth and twenty-second positions

159 (Fig. 1). OMNH 79346 and OMNH 79349 are mostly complete, whereas OMNH 79350 and

160 OMNH 79353 are incomplete. OMNH 79351 and OMNH 79352 are complete vertebrae from

161 the third to ninth vertebral positions (Fig. 2). OMNH 79347 consists of 11 articulated presacral

162 vertebrae, likely between the tenth and twenty-second positions (Fig. 3A). OMNH 79348

163 consists of the last presacral position, the first sacral vertebra, and a possible second sacral

164 vertebra in articulation (Fig. 3B-E). Despite the isolated nature of the specimens, the position of

165 the vertebrae can be inferred based on the morphology of the diapophyses, which change in

166 length, cross-sectional profile, and anteroposterior orientation along the vertebral column (White,

167 1939: Fig. 13).

168 All the vertebrae described here exhibit the swollen pre- and postzygapophyses that are

169 characteristic of Seymouria (White, 1939; Holmes, 1989). The first sacral vertebra in OMNH

17079348 exhibits the transition from the expanded zygapophyses of the trunk series to the more

171 transversely constricted morphology characteristic of the caudal series (White, 1939), with the

172 prezygapophyses being slightly more than twice the width of the postzygapophyses (Fig. 3B).

173 The neural spine of OMNH 79349 is strongly deflected to the right, as has been noted in other

174 specimens of Seymouria (Sullivan \& Reisz, 1999). Both OMNH 79351 and 79352 display the

175 broadly expanded diapophyses characteristic of the anteriormost presacral vertebrae in

176 Seymouria (Fig. 2). In OMNH 79352, the neural spine is bifurcated, with both projections

177 directed dorsolaterally; the neural spines of the other specimens are either broken or missing. 
178 Seymouria has been previously described as having an irregular distribution of bifurcated and

179 non-bifurcated spines along the presacral region between the tenth position and the twenty-

180 second position (White, 1939). OMNH 79352 appears to be the first record of bifurcation of the

181 neural spine in a vertebra from the anteriormost trunk. Although the seemingly complete co-

182 ossification of the neural arch and centrum suggests skeletal maturity, the maturity of these

183 vertebrae cannot be more definitively established given the known challenges of applying

184 skeletochronology to vertebral elements (Danto et al., 2016).

186 Humerus. OMNH 74721 is a complete right humerus, exhibiting the tetrahedral shape typical of

187 many reptiliomorphs (Fig. 4). The overall morphology matches that described by previous

188 authors (White, 1939; Sullivan \& Reisz, 1999) in being short and robust with the deltopectoral

189 crest following an L-shaped path. The proximal and distal ends are broadly expanded and are set

190 at an approximately 45-degree angle to each other with no distinct shaft separating the epiphyses.

191 The supinator process is oval in cross-section and located just distal to the short arm of the

192 deltopectoral crest (Fig. 4C). OMNH 74721 exhibits a keel that extends along the anteroventral

193 surface from the deltopectoral crest to the entepicondylar foramen (Fig. 4D); a similar crest has

194 been described by Sullivan \& Reisz (1999) but was not mentioned by White (1939). The

195 entepicondylar ridge runs along the ventral edge and expands proximally to form what may

196 represent the insertion site for the subcoracoscapularis on the posterior surface of the humerus,

197 near the glenoid articulation (Fig. 4B). Dorsal to this expansion is a pronounced tubercle for the

198 insertion of the latissimus dorsi muscle. The absence of an ectepicondylar foramen, the proximal

199 position of the insertions for the $m$. subcoracoscapularis and the $m$. latissimus dorsi, and the 
200 position and shape of the supinator process all correspond exactly to the descriptions of

201 Seymouria given by White (1939) and Sullivan and Reisz (1999).

202

203 Femur. ROMVP 80915 is a complete left femur (Fig. 5), the morphology of which corresponds 204 to previous descriptions (White, 1939; Sullivan \& Reisz, 1999). ROMVP 80916 and ROMVP 20581200 are partial left femora (Fig. 6). The element is short and robust. The insertion for the 206 puboischiofemoralis muscle is visible on the dorsal surface of the head (Fig. 5B, D). As is known 207 in Seymouria (White, 1939; Sullivan \& Reisz, 1999), the adductor crest extends posterolaterally

208 along the ventral surface of the femur from the trochanter to near the tibial condyle (Fig. 5F).

209 The smaller femur that was previously described by Sullivan and Reisz (1999; FMNH PR 2053)

210 was stated to have a prominent trochanter. This appears to remain constant throughout ontogeny, 211 as little difference in the relative size of the trochanter is seen between the smallest (ROMVP

212 81200) and largest specimens (ROMVP 80915 and 80916). The distal articular surface has been

213 described as following an M-shaped curve (White, 1939), but this may not be entirely accurate.

214 In ROMVP 80915, ROMVP 81200, and a smaller, more immature femur (FMNH PR 2053;

215 Sullivan \& Reisz, 1999: fig. 3), the distal surface is V-shaped, with the tip of the anterior arm

216 being bent ventrally (Fig. 5G), as opposed to the illustration given by White (1939: fig. 28) that

217 reconstructs this surface with both ends curving ventrally. However, it is also possible that the

218 shape of the distal surface is ontogenetically variable, as disparities in length suggest that the

219 specimen described by White (1939), measuring $6.4 \mathrm{~cm}$ in length, may be more mature than

220 ROMVP 80915 (5.5 cm), the largest complete femur from Richards Spur. 
222 Fibula. ROMVP 80917 is a complete left fibula (Fig. 7). Previous descriptions (White, 1939;

223 Sullivan \& Reisz, 1999) have commented only on the general shape of the element, to which

224 ROMVP 80917 corresponds exactly in that the medial surface is deeply concave, the lateral

225 surface is mostly straight with only a slight concavity, and the distal articular surface is more

226 expanded than the proximal surface, which itself is crescentic with its dorsal margin being

227 convex and its ventral margin being concave. Features that have not been described previously in

228 Seymouria but that are present in ROMVP 80917 are the pronounced muscle scar along the

229 proximal half of the lateral surface, which may represent the insertion site for the m. iliofibularis

230 (Fig. 7A-B, D; Romer, 1956), and the twisting of the fibular shaft such that the proximal and

231 distal heads lie in planes that are at an approximately 45-degree angle to each other (Fig. 7E-F).

\section{Histological Description}

234 Vertebra. ROMVP 81198, an isolated presacral neural arch of a small-bodied individual (Fig.

235 1E), and ROMVP 81199, a presacral neural arch with centrum of a larger individual (Fig. 1F),

236 were histologically sectioned. The transverse profile reveals a similar microanatomy and

237 histology to that of a previously sampled specimen (OMNH 73499) from Richards Spur (Danto

238 et al., 2016). The pleurocentrum of ROMVP 81199 is formed by two domains (Fig. 8), an well-

239 ossified yet porous periosteal domain along the ventrolateral margin of the element that is

240 formed by a thin layer of lamellar bone, and a less dense and more disorganized endochondral

241 domain with trabeculae; this is captured in both sagittal and transverse sections. Although the

242 suture between the pleurocentrum and the neural arch is not clearly defined externally, it is very

243 apparent in the transverse section in which an oblique separation (Fig. 8F) demarcates a largely

244 cartilaginous connection at the time of death. Neither the notochordal canal nor the neural canal 
245 were captured in the half-transverse section. The neural arches of ROMVP 81198 and 81199 are

246 very similar in transverse section. Each arch is comprised of a spongy bone texture with a hollow

247 interior. In the smaller ROMVP 81198 , the ventral portion of the arch is poorly ossified, with a

248 sparse network of trabecula (Fig. 9). The sagittal sections are also generally comparable, but a

249 few differences may be noted. Indentations on the anterior and posterior surfaces representing

250 the vestiges of the supraneural canal are present; these indentations are more prominent in the

251 larger ROMVP 81199, and in each specimen, the anterior indentation is more pronounced (Figs.

$2528 \mathrm{~A}, 9 \mathrm{~A})$. In both specimens, the cortex of the neural arch is much thicker along the posterodorsal

253 surface behind the neural spine and extending down to the posterior indentation of the

254 supraneural canal when compared to the anterior surface. The thickened region of cortex is far

255 more developed in the larger ROMVP 81199 . The neural spines are very poorly ossified. The

256 ventral portion of the arch, which roofs the neural canal, is thin in both specimens and exhibits

257 distinct remodelling (Figs. 8B, 9B). Remodelling is otherwise found mostly near the geometric

258 center of the element (Fig. 9B). A pair of closely spaced, distinctive growth lines can be

259 identified in the thickened region of ROMVP 81199 (Fig. 8A).

260 The three articulated vertebrae of OMNH 79348 were digitally sectioned using the

261 neutron tomography data (Fig. 10). Viewed in transverse section, the data reveal pronounced

262 differences in the compactness of the diapophyses; the diapophyses of the first sacral vertebra are

263 not only greatly expanded, as is visible externally, but are also substantially less porous than

264 those of either the presacral or the possible second sacral. The scan resolution is not sufficient to

265 permit tissue identification. 
267 Femur. ROMVP 80916 and ROMVP 81200 are partial left femora (Fig. 6); ROMVP 80916 is

268 equivalent in size to ROMVP 80915 and is broken distal to the trochanter, while ROMVP 81200

269 is substantially smaller (about $33 \%$ smaller) and is broken proximal to the trochanter. ROMVP

27080916 was histologically sectioned slightly proximal to the minimum diaphyseal circumference

271 (Fig. 11), while ROMVP 81200 was sectioned at this minimum region (Fig. 12). ROMVP 80915

272 was digitally sectioned at the minimum circumference (Fig. 13). All three femora are relatively

273 similar in their microanatomical and histological features. The cortex is relatively compact and

274 well-vascularized, comprised primarily of lamellar bone and with a plexiform arrangement of

275 vascular canals. Primary osteons and vascular canals are abundant in the growth zones of both

276 specimens (Figs. 11-12), but ROMVP 81200 appears to have a denser concentration, implying a

277 greater immaturity and a faster growth rate at the time of death. Remodelling is found at the

278 boundary of the medullary cavity in both specimens (Figs. 11C, 12C), but there is distinctly more

279 along the margin of the cavity in the larger ROMVP 80916 (Figs. 11-12). Secondary osteons

280 associated with this remodelling are found in both histologically sectioned specimens. The

281 medullary cavity is relatively open, although there is a network of trabeculae throughout;

282 secondary remodelling is present within this network, but calcified cartilage is absent. The

283 trabecular network appears to be less dense in the digital section of ROMVP 80915 (Fig. 13)

284 than in the histological section of the comparably sized ROMVP 80916 (Fig. 11), but this may be

285 a combination of a slightly more proximal plane of section in the latter and limitations on

286 scanning resolution $(25.2 \mu \mathrm{m})$ for the former.

287 In both histologically sectioned specimens, there are numerous circumferential lines;

288 none could be identified in the digital data for ROMVP 80195. In the smaller ROMVP 82100, at

289 least three lines are present (Fig. 12B). In the larger ROMVP 80916, at least seven lines are 
290 present (Fig. 11B). Based on the distribution of these lines as distinct clusters of closely spaced

291 lines in the poorly vascularized regions, these probably represent multiple rest lines within an

292 annulus (the poorly vascularized region), rather than clusters of lines of arrested growth (LAGs)

293 with highly uneven growth between deposition of each LAG. In ROMVP 80916, there is an

294 annulus partially preserved toward the extensor surface (away from the adductor crest) with at

295 least five rest lines present (Fig. 11A). Most of this annulus has been obliterated by remodelling,

296 and the rest lines are not uniformly distinct around their partial circumference. There are a few

297 vascular canals and primary osteons in this region near the border of the medullary cavity that

298 likely represent a partially preserved growth zone. The partial annulus is followed by a thicker

299 region of well-vascularized tissue (Fig. 11B). The external cortex is then formed by a thinner

300 layer of poorly vascularized tissue with at least three distinct rest lines, one of which essentially

301 marks the surface of the femur. In ROMVP 81200, there appear to be two zones of growth, one

302 adjacent to the medullary cavity and one along the external cortex, and one annulus with at least

303 three continuous rest lines (Fig. 12B). The second growth zone is not fully continuous

304 throughout, but the annulus can be traced circumferentially such that it can be determined to

305 precede this zone. The observation that the most peripheral zone in ROMVP 80916 is an

306 annulus, whereas the corresponding zone in ROMVP 81200 is a growth zone, indicates that the

307 animals died during different seasons. For both specimens, a minimum age of two years can thus 308 be estimated.

310 Discussion

311 Intraspecific variation. Described specimens of Seymouria illustrate the intraspecific variation

312 that occurs across the postcranial skeleton. For example, the porosity of the diapophyses differs 
313 between each vertebra in OMNH 79348, suggesting differential stress loading on each vertebra.

314 The identity of the vertebra immediately posterior to the first sacral has also been historically

315 debated; White (1939) and Berman et al. (2000) identified the element as a second sacral, while

316 Williston (1911), Watson (1918), and Berman, Reisz, and Eberth (1987) identified it as the first

317 caudal. White's (1939) argument was based on the presence of a rib extending anteriorly from

318 the vertebra in question to contact the rib of the first sacral, stating unequivocally that it must

319 have had a strong cartilaginous connection and was doubtlessly a functional second sacral

320 vertebra (p. 354). In contrast, Berman, Reisz, and Eberth (1987) noted that the rib of the debated

321 element curved posteriorly and thus could not contact the ilium or the rib of the first sacral,

322 negating any possibility of it forming a true second sacral. In the absence of a preserved rib in

323 OMNH 79348, we are unable to comment on whether the vertebra immediately following the

324 first sacral represents a definitive second sacral or the first caudal vertebra.

325 Compared to the smaller and presumably more immature humerus (FMNH PR 2054) that

326 was previously described from Richards Spur (Sullivan \& Reisz, 1999: fig. 2), many features on

327 OMNH 74721 are more developed. In FMNH PR 2054, the capitellum is indicated only by a

328 slight swelling, whereas in OMNH 74721 it is a distinct hemispherical facet. Mirroring this

329 disparity, the supinator process of FMNH PR 2054 remains connected to the capitellum by a

330 ridge of unfinished bone, whereas the process of OMNH 74721 is clearly delineated from the

331 distal articular surfaces by an emargination of smoothly finished bone.

332

333 Comparative external anatomy. Comparisons of Seymouria with many other

334 seymouriamorphs, especially with the discosauriscids, are complicated by the absence of

335 definitively adult individuals of many seymouriamorph taxa. Further complications arise from 
336 the evident taphonomic distortion and compaction of many seymouriamorph specimens. Any

337 discussion of comparative anatomy among seymouriamorphs, including the comparisons

338 presented here, must be viewed within the context of these limitations.

339 The vertebrae of Seymouria bear a number of marked differences from those of other

340 seymouriamorphs. In Ariekanerpeton, the presacral vertebrae differ in the level of ossification of

341 the neural arch, with the arches of the third to fifth vertebrae remaining separate and the sixth to

342 ninth arches being strongly co-ossified (Klembara \& Ruta, 2005). The neural spines of Kotlassia

343 are much higher than in Seymouria (Bystrow, 1944), whereas in Discosauriscus the spines are

344 short (Klembara \& Bartík, 2000), and in Ariekanerpeton the spines are either low or unossified

345 altogether (Laurin 1996b). The vertebrae of Utegenia have been described as indistinguishable

346 from those of Discosauriscus (Klembara \& Ruta, 2004). The oval cross-section of the

347 diapophyses is shared between Seymouria (White, 1939) and Kotlassia (Bystrow, 1944).

348 However, in Seymouria the diapophyses remain the same size but transition in orientation from

349 vertical to horizontal along the vertebral column (White, 1939), whereas the diapophyses of

350 Kotlassia maintain the same orientation but decrease in size along the column (Bystrow, 1944).

351 Unlike Seymouria and Kotlassia in which the articular surfaces of the prezygapophyses and the

352 postzygapophyses face directly dorsally and ventrally, respectively (White, 1939; Bystrow,

353 1944; Holmes, 1989), the surfaces of Discosauriscus and Ariekanerpeton face dorsomedially and

354 ventrolaterally (Klembara \& Bartík, 2000; Klembara \& Ruta, 2005). Seymouria, Kotlassia, and

355 Discosauriscus retain an open notochordal canal in adulthood (White, 1939; Bystrow, 1944;

356 Klembara \& Bartík, 2000). It is unknown whether the notochordal canals were retained in the

357 other seymouriamorphs (Klembara \& Ruta, 2004; 2005; Klembara, 2005; 2009; Bulanov, 2014).

358 Discosauriscus has only one sacral vertebra (Klembara \& Bartík, 2000), as in OMNH 79348. It 
359 is unclear whether Seymouria baylorensis and Seymouria sanjuanensis differ in the number of

360 sacral vertebrae (White, 1939; Berman, Reisz, \& Eberth, 1987, 2000), so this character cannot be

361 used to clarify the specific designation of this material.

362 The humerus of Seymouria is more extensively ossified than those of Utegenia or

363 Ariekanerpeton (Laurin, 1996a, 1996b; Klembara \& Ruta, 2005), in which the capitellum, the

364 trochlea, the supinator process, and the deltopectoral crest are indistinct in even the largest

365 individuals. In particular, the humerus of Utegenia has been described as "little more than a

366 stout, subcylindrical lump of bone" (Klembara \& Ruta, 2004: 77). It has been noted, however,

367 that the lack of ossification in Utegenia may represent ontogenetic immaturity (Klembara \&

368 Ruta, 2004). The humerus of Kotlassia is the slenderest of the seymouriamorphs and lacks an

369 entepicondylar foramen (Bystrow, 1944). Makowskia, Spinarerpeton, and Discosauriscus exhibit

370 the same massive, L-shaped deltopectoral crest extending from the proximal articular surface as

371 that seen in Seymouria (Klembara, 2005, 2009; Klembara \& Bartík, 2000). The humeri of

372 Makowskia and Spinarerpeton are described as having a broad shaft, a proximodistally short

373 entepicondyle, and an entepicondylar foramen that is open distally (Klembara, 2005, 2009); the

374 last feature has been recognized as likely being ontogenetic. Makowskia, Spinarerpeton, and

375 Discosauriscus differ substantially from Seymouria in having a well-developed insertion site for

376 the $m$. subcoracoscapularis and in lacking a supinator process (Klembara \& Bartík, 2000;

377 Klembara, 2005, 2009); in Seymouria, the former is represented by only a slight rugosity while

378 the latter is quite pronounced (White, 1939). The humeri of Discosauriscus and Ariekanerpeton

379 have been reported with a lesser degree of twisting, with the planes of the proximal and distal

380 ends being at an approximately 38-degree angle (Klembara \& Bartík, 2000; Klembara \& Ruta,

381 2005). The positioning and degree of development of the insertions for the $m$. 
382 subcoracoscapularis and m. latissimus dorsi are roughly equivalent in Discosauriscus as in

383 Seymouria (Klembara \& Bartík, 2000).

384 As with the humerus, the femur of Seymouria is more ossified than in Utegenia or

385 Ariekanerpeton (Laurin 1996a, 1996b); the femur of Utegenia has been described as featureless

386 (Klembara \& Ruta, 2004). The femur of Makowskia is known but has only been described as

387 having a crescentic proximal articular surface with a deep intertrochanteric fossa as in Seymouria

388 (Klembara, 2005), and the only corresponding figure is a simplified line drawing. The femur of

389 Spinarerpeton has been similarly described and figured in limited detail (Klembara, 2009). The

390 femur of Microphon is much more gracile than in Seymouria with less pronounced expansion of

391 the epiphyses and a proportionally longer, narrower shaft (Bulanov, 2014). Microphon also

392 differs from Seymouria in that the adductor crest extends towards the fibular condyle (Bulanov,

393 2014), as opposed to the tibial condyle as occurs in Seymouria and Discosauriscus (Klembara \&

394 Bartík, 2000). In addition, the intertrochanteric fossa of Microphon is approximately one-third

395 the length of the femur (Bulanov, 2014), whereas in Seymouria it extends approximately halfway

396 along the element. Kotlassia appears to be intermediate between these two conditions and

397 exhibits a starker contrast between the slender shaft and the broadly expanded epiphyses

398 (Bystrow, 1944: fig. 9). A feature found in the femora of Microphon and Kotlassia and in

399 ROMVP 80915, though perhaps not all specimens of Seymouria, is the lesser development of the

400 trochanter (Bystrow, 1944); in Microphon, the trochanter seems to not be developed at all

401 (Bulanov, 2014). The femur of Discosauriscus is similar to that of Seymouria in overall

402 morphology but is more gracile (Klembara \& Bartík, 2000: fig. 25).

403 The fibulae of Kotlassia and Utegenia have not been illustrated or described in sufficient

404 detail to allow for accurate comparison with Seymouria. The fibula of Ariekanerpeton has only 
405 been described as being poorly preserved with unfinished epiphyses (Klembara \& Ruta, 2005).

406 In Makowskia and Discosauriscus, the fibula is similar to Seymouria in being deeply concave

407 medially with only a slight concavity on the lateral surface (Klembara \& Bartík, 2000; Klembara, 408 2005). The fibula of Spinarerpeton is unknown (Klembara, 2009).

409

410 Histological interpretations and comparisons.

411 Contextualizing the histological data of the specimens of Seymouria is complicated by

412 the paucity of work on other stem amniotes, let alone seymouriamorphs specifically. Limb

413 elements of Seymouria have never been histologically analyzed. The only other seymouriamorph

414 femur to be histologically sampled is that of the European Discosauriscus, the femur of which is

415 characterized by a parallel-fibered endosteal matrix with sparse vascularization comprised of

416 radially and longitudinally arranged canals in small individuals that shifts to being dominated by

417 radial vasculature in adults (Sanchez et al., 2008). Seymouria exhibits a lamellar matrix with a

418 plexiform arrangement of the vasculature in the femur, and the degree of vascularization far

419 exceeds that figured for Discosauriscus. The increased vascularization is indicative of relatively

420 fast growth at the time of death in the sampled specimens of Seymouria, which also suggests

421 relative immaturity. Skeletochronological markers also differ between the taxa. Discosauriscus

422 possesses numerous, well-defined and evenly spaced LAGs, whereas Seymouria is characterized

423 by distinctive growth zones and annuli bearing numerous closely spaced rest lines but without

424 clear LAGs. Similar variation in skeletochronological markers has been reported in the Late

425 Triassic metoposaurids Dutuitosaurus from Morocco and Metoposaurus from Poland; this

426 disparity was hypothesized to be the result of differing seasonal activity patterns associated with

427 climatic differences across paleolatitudinal gradients (Konietzko-Meier \& Klein, 2013). Lastly, 
428 the medullary spongiosa is distinctly less developed in Discosauriscus (Sanchez et al., 2008:fig.

429 2); the significance of this is unclear in the absence of additional data. It may relate to overall

430 body size, as extant lissamphibians, relatively small in comparison to Seymouria, typically lack

431 medullary spongiosa; however, the larger cryptobranchids possess a spongiosa (e.g., Laurin,

432 Canoville, \& German, 2011). Similarly, small, semi-terrestrial to terrestrial temnospondyls also

433 have little to no spongiosa (e.g., McHugh, 2015) compared to the larger Eryops with a much

434 denser spongiosa (e.g., Konietzko-Meier, Shelton, \& Sander, 2016).

435 Comparisons with other Paleozoic tetrapods are also limited by a paucity of comparative

436 work. Of the major Paleozoic clades (e.g., pelycosaurian synapsids, 'lepospondyls’),

437 temnospondyls are the best-sampled (Sanchez et al., 2010a; Sanchez et al., 2010b; McHugh,

438 2014; Konietzko-Meier, Shelton \& Sander, 2016). The relative thickness of the cortex and the

439 development of the medullary spongiosa are most comparable to that of the co-occurring

440 trematopid Acheloma dunni, a terrestrial taxon (Sanchez et al., 2010b; Quemeneur, de Buffrénil

$441 \&$ Laurin, 2013). The spongiosa is less developed than in either definitively aquatic taxa such as

442 the late Permian rhinesuchid Rhinesuchus (McHugh, 2014) or in controversially aquatic taxa

443 such as the early Permian eryopid Eryops (Sanchez et al., 2010b; Quemeneur, de Buffrénil \&

444 Laurin, 2013; Konietzko-Meier, Shelton \& Sander, 2016), and the cortex is not extensively

445 thickened as in the definitively aquatic dvinosaur Trimerorhachis (Sanchez et al., 2010b;

446 Quemeneuer et al., 2013). A large number of Mesozoic temnospondyls, which are predominantly

447 aquatic, have also been sampled (Steyer et al., 2004; Konietzko-Meier \& Sander, 2013; Sanchez

$448 \&$ Schoch, 2013). Many of these taxa exhibit similar structure to that of Trimerorhachis, often

449 with a high degree of pachyostotic development and with greatly reduced or nearly absent

450 medullary cavities. McHugh (2015) sampled the small-bodied Early Triassic lydekkerinid 
451 Lydekkerina, a semi-aquatic taxon with terrestrial capabilities (e.g., Pawley \& Warren, 2005;

452 Canoville \& Chinsamy, 2015) and the amphibamiform Micropholis, a fully terrestrial taxon (e.g.,

453 Schoch \& Rubidge, 2005). Both taxa exhibit a similar histological and microanatomical

454 organization to that of terrestrial Paleozoic temnospondyls and to that of Seymouria.

455 Collectively, the temnospondyl comparisons support an inferred terrestrial lifestyle of

456 Seymouria. However, it is important to note that the spongiosa of Seymouria is more developed

457 than in any of the co-occurring terrestrial temnospondyls at Richards Spur (Castanet et al., 2003;

458 Quemeneur, de Buffrénil \& Laurin, 2013; Richards, 2016) in which the spongiosa is either

459 weakly developed (Trematopidae) or virtually non-existent (Dissorophidae, Amphibamiformes).

460 However, it is comparable in the developed medullary spongiosa to that of Eryops, the degree of

461 terrestriality of which has long been debated (Konietzko-Meier, Shelton, \& Sander, 2016, and

462 references therein). The significance of the spongiosa in Seymouria is uncertain at present and

463 warrants further work to compare with other co-occurring taxa and with more closely related

464 stem amniotes.

465 The vertebral histology is also difficult to compare with coeval tetrapods, let alone with

466 closely related taxa. Vertebrae are uncommon in histological studies compared to limb elements,

467 and most studies that that have examined the vertebrae of Paleozoic tetrapods have focused on

468 the inter- and pleurocentra (Konietzko-Meier, Danto \& Gadek, 2014; Danto et al., 2017, 2019).

469 However, both the centra and the neural arches contribute valuable information regarding the

470 lifestyle of Seymouria. Previous workers have often suggested that the neural arch would have

471 been subject to strong biomechanical constraints during locomotion in early tetrapods (Rockwell,

472 Evans \& Pheasant, 1938; Olson, 1976; Holmes, 1989). The prominent expansion of the neural

473 arch and the development of the zygapophyses in Seymouria lends support to this hypothesis. 
474 Discosauriscus is the only other seymouriamorph to have its internal vertebral anatomy

475 examined (Danto et al., 2016). The main difference is in the construction of the neural arch,

476 which is comprised of thick, compact lamellar bone in Discosauriscus; in contrast, the neural

477 arch of Seymouria is largely hollow. Based on the size of the sampled Discosauriscus material,

478 the individual was likely premetamorphic and still aquatic, which would explain the higher

479 degree of ossification. Whether this might have changed in later stages of ontogeny if or when

480 individuals metamorphosed into a terrestrial adult form remains unknown. Beyond

481 seymouriamorphs, neural arches have not been sampled in many clades, which may be because

482 most Paleozoic tetrapod clades have multipartite vertebrae in which the arch readily detaches

483 from the centra during preservation. Furthermore, isolated neural arches have not traditionally

484 been utilized as an ideal case study for exploring histological questions compared to either the

485 centra or to other postcranial elements. Danto et al. (2016) sampled a number of Paleozoic

486 lepospondyl taxa in which neural arches were preserved. Some of the aquatic taxa (e.g., an

487 indeterminate nectridean) exhibit a similar spongy bone composition of the arch, but the interior 488 of the arch is relatively well-ossified with little empty space.

489

490

491

492

493

494

495

496

Skeletochronological interpretations. In the absence of comparative histological data,

most inferences regarding the life history of seymouriamorphs have been based on external anatomy of different skeletal regions. For example, most individuals of Discosauriscus retain lateral line canals on the skull, indicating an aquatic lifestyle, but this may also reflect a biased relative abundance of premetamorphic individuals in the fossil record (e.g., Klembara et al., 2006). Although definitive adults of this taxon, terrestrial or otherwise, are unknown (Klembara, 2001), previous authors have inferred that Discosauriscus underwent metamorphosis (Klembara, 
497 1995), or that if some species were paedomorphic, were derived from an ancestor that did

498 metamorphose into a terrestrial adult (e.g., Boy \& Sues, 2000). For Discosauriscus austriacus,

499 Sanchez et al. (2008) reported that metamorphosis occurred around the sixth year of life.

500 Although not explicitly stated as such, determination of metamorphosis in that study was

501 rendered feasible through the sampling of limb material of Discosauriscus from articulated

502 skeletons that would permit correlation of the skeletochronological data from the histological

503 analysis with external osteological features traditionally used for relative age determination.

$504 \quad$ Characterizing ontogeny in Seymouria is complicated by a general paucity of associated

505 postcrania compared to Discosauriscus such that most characterizations are solely based on the

506 cranium (e.g., Klembara et al., 2006, 2007). Indeed, it is not known for certain that Seymouria

507 underwent metamorphosis, as no larval forms have been recovered. The smallest reported

508 specimen is one from the Bromacker quarry with a skull measuring $2.1 \mathrm{~cm}$ (Berman \& Martens,

509 1993), but the preservation is too poor to be described for comparative anatomical purposes.

510 Most of the other well-described cranial specimens exceed $80 \mathrm{~cm}$ (e.g., Berman, Reisz, \&

511 Eberth, 1987), and small specimens remain poorly represented (e.g., Klembara et al., 2006).

512 Simultaneously, the histological signals of metamorphosis in early tetrapods, if they exist,

513 remain poorly understood. In extant lissamphibians, which may be the most appropriate extant

514 analogue for seymouriamorphs, there is often a 'transformation mark' (Schroeder \& Baskett,

515 1968) or a 'metamorphosis line' (Rozenblut \& Ogielska, 2005) that demarcates overwintering

516 following metamorphosis. Unfortunately, the criteria for identifying this line are somewhat

517 ambiguous in the literature beyond it being the closest circumferential line to the medullary

518 cavity and likely being closely spaced to the first LAG. Identifying this feature may thus rely

519 mainly on an absence of endosteal resorption (present in our sectioned specimens) that would 
520 obliterate this mark. The line has a similar appearance to LAGs (e.g., Tsiora \& Kyriakopoulou-

521 Sklavounou, 2002), and there is some debate over whether there is a correlation of this line with

522 deposition of woven-fibered bone (e.g., see Castanet \& Smirina, 1990; Guarino et al., 2003). To

523 the best of our knowledge, this feature has never been identified in a Paleozoic tetrapod, and the

524 applicability of crown lissamphibian life history to seymouriamorphs on the amniote stem is

525 unknown.

526

As a result, determining whether a specimen of Seymouria is 'postmetamorphic' is based

527 largely on an established precedent of using external features from which admittedly arbitrary

528 and gradational terms such as 'juvenile,' 'sub-adult,' and 'adult' are derived. It bears noting that

529 these terms may refer to different biological attributes (e.g., sexual maturation vs. the process of

530 metamorphosis) and may be used differently by various workers. With respect to ROMVP

531 80916, the large partial femur that was sectioned, there is a well-established precedent for

532 identifying the element as belonging to a probable 'adult' that had completed metamorphosis.

533 ROMVP 80916 is incomplete, but the preserved portion is the same size as the complete

534 ROMVP 80915, which measures $5.5 \mathrm{~cm}$ in length and which is on the larger end of previously

535 reported specimens (e.g., $6.4 \mathrm{~cm}$; White, 1939). Based on comparisons with articulated

536 specimens of Seymouria (Berman, Reisz, \& Eberth, 1987, 2000), this femur would belong to an

537 individual with a skull length exceeding $10 \mathrm{~cm}$, which falls well within a range for which

538 specimens have been previously described as 'adults.' Femora of the previously described

539 articulated skeletons are smaller than ROMVP 80916 yet the skulls possess numerous features

540 accepted as evidence for both somatic maturity and terrestriality, such as the absence of lateral

541 line grooves, ossified carpals and tarsals, firmly interdigitated sutures, and pronounced

542 ornamentation (Boy \& Sues, 2000). ROMVP 82100 is smaller, measuring only $2.6 \mathrm{~cm}$ as 
543 preserved. By comparison with ROMVP 80915, assuming isometric scaling of the element,

544 ROMVP 81200 would have been around $4.2 \mathrm{~cm}$ in length when preserved. Using this estimate

545 and comparisons with articulated specimens, the skull of this individual would have been around

$5468 \mathrm{~cm}$, which is only slightly below the lower size bound reported for most specimens of

547 Seymouria (e.g., Berman, Reisz, \& Eberth, 1987) and which would at least represent a 'sub-

548 adult' based on previous designations. Further evidence for a postmetamorphic determination

549 may be found in the nature of the preservational environment of Richards Spur. Beyond the

550 enigmatic and extremely rare aïstopod Sillerpeton permianum, there is no evidence of aquatic

551 tetrapods, either larval forms of metamorphosing adults or obligately aquatic adult forms, even

552 though material of very small-bodied tetrapods is captured (MacDougall et al., 2017). Regardless

553 of whether this represents a biased sample, it is clear that the fissure fills were not conducive to

554 the capture of aquatic tetrapods.

555 Based on a postmetamorphic interpretation of the sectioned material, the onset of

556 metamorphosis in Seymouria may thus be constrained to probably occurring by the second year

557 of life. It may be inferred that the larger ROMVP 81096 was probably older than two years,

558 although this cannot be proven nor can the amount of growth cycles lost to remodeling

559 determined at present. Metamorphosis in Seymouria occurred much earlier than in

560 Discosauriscus, which was suggested to undergo a delayed metamorphosis around the sixth year

561 of life (Sanchez et al., 2008). The more compact and sparsely vascularized lamellar bone of

562 Discosauriscus also support interpretations of a slower growth and a protracted aquatic larval

563 stage in this taxon (Sanchez et al., 2008). This disparity among closely related taxa may reflect

564 the different environments that these taxa inhabited (correspondent with their differing

565 lifestyles), as Seymouria is primarily found in fluvial environments of North America, and 
566 Discosauriscus is primarily found in lacustrine settings in Europe. Both taxa likely experienced

567 distinct seasonality, but the presence of distinct LAGs in Discosauriscus suggests a stronger

568 relative influence of environmental fluctuations on this taxon. Some seasonality at Richards

569 Spur, previously demonstrated through other lines of evidence (e.g., Woodhead et al., 2010;

570 MacDougall et al., 2017) is evident in our samples from the clearly defined annuli and growth

571 zones (Figs. 11-12), and it seems probable that these environmental conditions (particularly the

572 ephemerality of bodies of water) would have favored an early onset of metamorphosis in

573 Seymouria. Taxa living in the same habitat and experiencing similar conditions can exhibit

574 different responses to those conditions - amniotes are typically less constrained by water stress

575 relative to non-amniotes, for example. A hypothesis of variable responses to similar climate at

576 Richards Spur is supported by the differing skeletochronological records of co-occurring

577 tetrapods from the site. The dissorophoid temnospondyls exhibit clear LAG patterns (Richards,

578 2016; Gee, Haridy, \& Reisz, in press), whereas the varanopid synapsids exhibit a mixture of

579 LAGs and annuli with growth zones (Huttenlocker \& Shelton, 2020), and the captorhinid

580 eureptiles exhibit only annuli with growth zones (Peabody, 1961; Richards, 2016; Huttenlocker

$581 \&$ Shelton, 2020). Other hypotheses to explain the differing patterns include secondary

582 environmental factors that may themselves be influenced by climate but in more nuanced and

583 asymmetrical fashions, such as prey availability or limited spatial occupation within the habitat.

$584 \quad$ Future work will be necessary to identify histological markers of pre- versus

585 postmetamorphic life stages. The present study cannot inform further on this because of the

586 absence of definitive larval specimens of Seymouria, which in turn creates more uncertainty

587 regarding the nature of metamorphosis, if it occurred in this taxon, as well as the external

588 osteological changes associated with this process if it did. Even if our interpretation of the 
589 sampled specimens as postmetamorphic is accepted, the timing of either the onset or completion

590 of metamorphosis relative to the time of death remains unclear. In order to more precisely

591 constrain histological markers of metamorphosis will require sampling of taxa, such as

592 Discosauriscus, for which metamorphosis is definitively known and for which osteological

593 changes associated with this process are well-documented.

Lifestyle interpretations. In early tetrapods, interpretations of lifestyle (e.g., aquatic vs.

terrestrial) are often based on the presence or absence of features such as lateral line grooves and the degree of development of external features of the limbs (e.g., Moodie, 1908; Schoch, 2002; Witzmann, 2016). Histology has more recently been utilized as a means to further test these hypotheses by means of comparisons with extant taxa in which mode of life can be definitively observed and with the classically utilized external anatomical features (Germain \& Laurin, 2005; Kriloff et al., 2008; Sanchez et al., 2010; Quemeneur, de Buffrénil \& Laurin, 2013; KonietzkoMeier, Shelton, \& Sander, 2016). Seymouria is widely accepted to lack lateral line grooves, although they have been suggested by some to have been present in juveniles (Berman \& Martens, 1993, but see Klembara et al., 2006), suggesting a transition in lifestyle throughout ontogeny. Additionally, the limb bones are well-developed, with prominent attachment sites for musculature and distinct processes (Figs. 4-5), and the neural arches are greatly expanded compared to other Paleozoic tetrapods with prominent zygapophyses inferred to have supported the axial column in a terrestrial animal (Sullivan \& Reisz, 1999). Our data further corroborate the interpretation of the Richards Spur locality as an assemblage dominated by terrestrial fauna

610 (MacDougall et al., 2017). 
611 The centra also contribute information through inferences on the skeletal mass of the

612 element(s). The two traditionally utilized criteria are the thickness of the periosteal domain and

613 the presence or absence of calcified cartilage. Greatly thickened domains (pachyostosis) and

614 retention of calcified cartilage throughout ontogeny are frequently seen in large-bodied aquatic

615 temnospondyls and probably served to increase the skeletal mass for buoyancy control (Danto et

616 al., 2016). In both Discosauriscus and Seymouria, the periosteal domain is relatively thin, and

617 calcified cartilage is primarily found around the notochordal canal (Danto et al., 2016). In

618 Seymouria, this is the only location of this tissue, whereas calcified cartilage occurs sporadically

619 in the endochondral domain of at least immature individuals of Discosauriscus.

620 What then can be concluded regarding the histological data from Seymouria postcrania

621 and the lifestyle of the taxon? The femoral microanatomy, specifically the relatively thin cortex

622 and the modest development of the medullary spongiosa, is more compatible with that of a

623 terrestrial animal by comparison with other Paleozoic tetrapods (primarily temnospondyls) that

624 have been inferred to be terrestrial (e.g., Sanchez et al., 2010b; Quemeneur, de Buffrénil \&

625 Laurin, 2013). Based on studies of femoral and tibial microanatomy in extant tetrapods (Kriloff

626 et al., 2008; Quemeneur, de Buffrénil \& Laurin, 2013), these features also support a primarily

627 terrestrial lifestyle. Collectively, this corroborates the conclusions of previous authors that

628 Seymouria was most likely a terrestrial animal (White, 1939; Berman \& Martens, 1993; Sullivan

629 \& Reisz, 1999; Marchetti, Mujal \& Bernardi, 2017). The vertebral histology also confers support

630 for a terrestrial lifestyle. The periosteal domain is thin, calcified cartilage is sparse and confined

631 to the margin of the notochordal canal, and the neural arch is largely hollow. These data

632 correspond favorably with the broad expansion of the arch and the zygapophyses, which Sullivan

$633 \&$ Reisz (1999) interpreted to be for the stiffening of the axial column following White (1939). 
635 Terrestriality in seymouriamorphs. Assessing the range of ecologies among seymouriamorphs

636 from a macroevolutionary standpoint is important because the group has historically been

637 regarded as being well-situated for understanding the associated skeletal modifications

638 associated with terrestriality. Seymouria is one of the best seymouriamorphs for examining such

639 modifications because complete, articulated skeletons are known (e.g., Berman, Reisz, \& Eberth,

640 1987), but it then becomes important to assess whether a terrestrial or aquatic lifestyle is the

641 plesiomorphic state among seymouriamorphs. Given that seymouriamorphs, and reptiliomorphs

642 more broadly, are frequently used as exemplars for the skeletal changes associated with

643 terrestrial adaptation, clarifying the primitive condition of this group is critical for informing

644 accurate comparisons. A conceptual phylogeny, adapted from Klembara (2011), is presented in

645 Figure 14, illustrating the distribution of terrestriality among seymouriamorphs.

646 Our data provide strong evidence at the histological and the microanatomical scales to

647 support the longstanding hypothesis of terrestriality in Seymouria. This is not a particularly

648 controversial idea; numerous aspects of the external morphology, such as the well-ossified limbs

649 and the massively expanded vertebrae have long been cited as evidence for this lifestyle (Romer,

650 1956). Although Berman and Martens (1993) described a possible indication of a lateral line

651 system in juvenile specimens of $S$. sanjuanensis from Germany, subsequent work (Klembara et

652 al. 2006) on an early juvenile did not find any evidence for a lateral line system in other $S$.

653 sanjuanensis from the same locality. As such, while it is often inferred that Seymouria underwent

654 metamorphosis as with other seymouriamorphs and a number of other terrestrial tetrapods (e.g.,

655 some temnospondyls), definitive aquatic larval forms and morphological transitions associated

656 with the presumed metamorphosis are unknown. 
At least one other seymouriamorph, Karpinskiosaurus, is also represented only by

658

659

660

661

662

663

664

665

666

667

668

669

670

671

672

673

674

675

676

677

678

679

specimens that lack lateral line grooves (Klembara, 2011). Kotlassia has also been historically

regarded as lacking lateral line grooves (e.g., Bystrow, 1944), but the Kotlassia of most previous authors is actually a combination of material referable to the type species, Kotlassia prima, and material properly referable to Karpinskiosaurus (see Bulanov, 2002 and Klembara, 2011, for discussion). Whether these grooves are definitively absent in the holotype of Ko. prima is not apparent from previous works that accounted for this historical discrepancy. For

Karpinskiosaurus and Seymouria, it has been proposed that these taxa underwent metamorphosis relatively early in their development and lived on land for the majority of their lives (Klembara, 2011).

In contrast, most other seymouriamorphs are known from individuals with lateral line grooves, including Ariekanerpeton (Klembara \& Ruta, 2005), Discosauriscus (Klembara, 1996), Spinarerpeton (Klembara, 2009), and Utegenia (Malakhov, 2000). The most recent phylogenetic analysis that focused on seymouriamorph phylogeny is that of Klembara (2011), which followed a series of anatomical work that re-described virtually all known seymouriamorphs. Mapping the distribution of ecologies onto this topology suggests that seymouriamorphs are primitively aquatic (Utegenia being the earliest diverging taxon) and with two separate shifts to terrestriality, one in Karpinskiosaurus and one in Seymouria (Fig. 14). However, caution must be exercised in inferring the phylogeny of a clade in which metamorphosis is known to occur because biases in the record of premetamorphic larval forms versus that of postmetamorphic terrestrial adults (if such determinations can be made to begin with) can produce misleading data. As with Seymouria (Berman et al., 2000), it has been proposed that Discosauriscus transitioned from an aquatic to terrestrial lifestyle throughout its ontogeny, but even the largest known specimens of 
680 Discosauriscus are believed to be juveniles, and none have been recovered from the terrestrial

681 environments that the adult individuals may have inhabited (Klembara, Martens \& Bartik, 2001).

682 This may relate to a relatively protracted larval stage that was recovered through the histological

683 work of Sanchez et al. (2008) in which metamorphosis may not have begun until year six of an

684 individual's life. The latest phylogenetic analyses (Klembara, 2011) do not bear out the slippage

685 that is predicted when coding taxa based on immature specimens (i.e. Discosauriscus is a highly

686 nested seymouriamorph), but this does not negate the potential for this disparity to affect the

687 phylogeny. Ariekanerpeton, Spinarerpeton, and Utegenia are also likely represented only by

688 juveniles (Klembara \& Ruta, 2003, 2005; Klembara, 2009), which warrants consideration.

689

690 Conclusions

691 Histology offers one avenue for exploring the diversity of life histories within a clade

692 through well-documented taxa (e.g., Discosauriscus, Seymouria) and for improving hypotheses

693 and predictions regarding those of more poorly represented taxa with limited ontogenetic data.

694 The correlation of the skeletochronological data from our histological analysis with the relative

695 size and development of external features of the sampled femora substantiate the hypothesis that

696 Seymouria was a rapidly metamorphosing taxon that spent most of its life on land (Klembara,

697 2011). This life history may explain why it is predominantly found in fluvial deposits of south-

698 southwestern North America and the upland Bromacker locality along with other highly

699 terrestrial tetrapods whereas the slower growing Discosauriscus is restricted to lacustrine

700 environments of Europe. A relatively early onset of metamorphosis may also account for the

701 absence of larval forms of Seymouria (i.e. a short aquatic larval stage) and the probable spatial

702 separation of larvae from the fluvial environments that preserved the adults (niche partitioning 
703 between life stages). Recovery of small and presumably immature specimens of Seymouria will

704 be required to further explore the taxon's life history and to contextualize it with other terrestrial 705 tetrapods.

706 In the sense that terrestriality in adults of Seymouria has not been widely questioned, our 707 most novel data, the histological data, are not necessarily surprising. However, this should not 708 diminish the value of these data; testing hypotheses using multiple approaches is important for 709 assessing the rigor of such hypotheses. The existing histological framework and understanding of seymouriamorph development remains largely confined in traditional interpretations of relative

711 maturity based on external features and their development, and there is an extensive precedent

712 for the utility of histology (among other more recently accessible methods) to further explore

713 paleobiological attributes of extinct taxa. Our interpretations of the data are somewhat limited, in

714 part by sample size, but also in part by the absence of a substantive body of comparative data. It

715 is unclear, for example, what to make of the persistence of a modestly developed medullary

716 spongiosa in the femur of Seymouria, either compared to Discosauriscus or to other more

717 distantly related terrestrial tetrapods (though see our previous comment regarding the potential

718 for there to be a size correlation). Taken in isolation, the presence of this spongiosa could

719 indicate that Seymouria was more semi-terrestrial than previously believed, at least at the

720 captured stages of its life history, but it bears reiterating that microanatomy captures more than 721 just a signal of ecological lifestyle, such as signals from phylogeny or from life history. Lifestyle

722 is also gradational, both between and within taxa, such that binning taxa into discrete categories

723 can prove challenging. Our ontogenetic trends are more accurately stated as two partial points

724 within the developmental trajectory, and the opportunity remains to explore ontogeny further

725 within Seymouria across all regions of the skeleton. 


\section{Institutional Abbreviations}

728 FMNH Field Museum of Natural History, Chicago, IL, USA

729 OMNH Sam Noble Oklahoma Museum of Natural History, Norman, OK, USA

730 ROMVP Royal Ontario Museum, Toronto, ON, Canada

731

\section{Acknowledgements}

733 Thanks to Kevin Seymour (ROMVP) and Jennifer Larsen (OMNH) for assistance with collection

734 numbers. Thanks to Ashley Reynolds and Jade Simon (ROMVP) for assisting KDB in the

735 production of histological thin sections. Thanks to Yara Haridy (Museum für Naturkunde Berlin)

736 for discussion of histology. Thanks to Sophie Sanchez (Uppsala University) for sharing thin

737 section images of Discosauriscus.

738

739 Note to reviewers/editor: embargoed data during review can be viewed on MorphoBank using a

740 special log-in: username "3549” and password "ROMVP80915”.

741

742 References

743 Amalitzky, V. P. 1921. Seymouriidae. North Dvina Excavations of Prof. V. P. Amalitzky 2:1-14.

744 Petrograd Academy of Sciences, Petrograd. [In Russian].

745 Bazzana, K. D., Gee, B. M., Bevitt, J. J., and Reisz, R. R. 2020 (for 2019). Neurocranial anatomy

746 of Seymouria from Richards Spur, Oklahoma. Journal of Vertebrate Paleontology

747 e1694535. doi: 10.1080/02724634.2019.1694535 
748 Berman, D. S. and Martens, T. 1993. First occurrence of Seymouria (Amphibia: Batrachosauria)

749 in the Lower Permian Rotliegend of Central Germany. Annals of Carnegie Museum 62:63-

$750 \quad 79$.

751 Berman, D. S., Henrici, A. C., Sumida, S. S., \& Martens, T. 2000. Redescription of Seymouria

752 sanjuanensis (Seymouriamorpha) from the Lower Permian of Germany based on complete,

753 mature specimens with a discussion of paleoecology of the Bromacker locality assemblage.

754 Journal of Vertebrate Paleontology 20:253-268.

755 Berman, D. S., Reisz, R. R., and Eberth, D. A. 1987. Seymouria sanjuanensis (Amphibia,

756 Batrachosauria) from the Lower Permian Cutler Formation of north-central New Mexico

757 and the occurrence of sexual dimorphism in that genus questioned. Canadian Journal of

$758 \quad$ Earth Sciences 24:1769-1784.

759 Broili, F. 1904. Permische Stegocephalen und Reptilien aus Texas. Palaeontographica 51:1-120.

760 Bulanov, V. V. 2002. Karpsinkiosaurus ultimus (Seymouriamorpha, Parareptilia) from the Upper

761 Permian of European Russia. Paleontological Journal 36:72-79.

762 Bulanov, V. V. 2014. New finds of Microphon exiguus (Seymouriamorpha, Kotlassiidae) in the

763 Severodvinian beds of the Sukhona River Basin, Russia. Paleontological Journal 48:633-

6464

765 Bystrow, A. P. 1944. Kotlassia prima Amalitzky. Bulletin of the Geological Society of America

766 $55: 379-416$.

767 Canoville, A., and Chinsamy, A. 2015. Bone microstructure of the stereospondyl Lydekkerina 768 huxleyi reveals adaptive strategies to the harsh post Permian-extinction environment. The $769 \quad$ Anatomical Record 298:1237-1254. 
770 Castanet, J., and Smirina, E. M. 1990. Introduction to the skeletochronological method in 771 amphibians and reptiles. Annales des Sciences Naturelles 13e Sér 11:191-196

772 Castanet, J., Francillon-Vieillot, H., De Ricqlès, A. and Zylberberg, L. 2003. The skeletal 773 histology of the Amphibia. Amphibian biology 5:1598-1683.

774 Danto, M., Witzmann, F., Fröbisch, N., and Claessens, L. 2016. Vertebral development in 775 Paleozoic and Mesozoic tetrapods revealed by paleohistological data. PLoS ONE 776 $11: \mathrm{e} 0152586$.

777

778

779

780

781

782

783

784

785

786

787

788

789

790

791

792

Danto, M., Witzmann, F., Pierce, S. E. and Fröbisch, N. B. 2017. Intercentrum versus pleurocentrum growth in early tetrapods: A paleohistological approach. Journal of morphology 278:1262-1283.

Danto, M., Witzmann, F., Kamenz, S. K. and Fröbisch, N. B. 2019. How informative is vertebral development for the origin of lissamphibians?. Journal of Zoology 307:292-305.

Garbe, U., Randall, T., Hughes, C., Davidson, G., Pangelis, S., and Kennedy, S. J. 2015. A new neutron radiography / tomography / imaging station DINGO at OPAL. Physics Procedia 69:27-32.

Gee, B. M., Haridy, Y., and Reisz, R. R. in press. Histological skeletochronology indicates developmental plasticity in the early Permian stem lissamphibian Doleserpeton annectens. Ecology \& Evolution. doi: 10.1002/ece3.6054

Guarino, F. M., Lunardi, S., Carlomagno, M., and Mazzotti, S. 2003. A skeletochronological study of growth, longevity, and age at sexual maturity in a population of Rana latastei (Amphibia, Anura). Journal of Biosciences 28:775-782.

Holmes, R. 1989. Functional interpretations of the vertebral structure in Paleozoic labyrinthodont amphibians. Historical Biology 2:111-124. 
793 Holly, C. 2004. Grouped ZProjector (forImageJ), https://imagej.nih.gov/ij/plugins/group.html.

794 Holly Mountain Software, Waterville, Maine, USA. Accessed Jan 21, 2017.

795 Huttenlocker, A. K., and Shelton, C. D. 2020. Bone histology of varanopids (Synapsida) from

796 Richards Spur, Oklahoma, sheds light on growth patterns and lifestyle in early terrestrial

797 colonizers. Philosophical Transactions of the Royal Society B 375:20190142.

798 Klembara, J. 1995. The external gills and ornamentation of skull roof bones of the Lower

799 Permian tetrapod Discosauriscus (Kuhn 1933) with remarks to its ontogeny.

$800 \quad$ Paläontologische Zeitschift 69:265-281.

801 Klembara, J. 1996. The lateral line system of Discosauriscus austriacus (Makowsky 1876) and

802 the homologization of skull roof bones between tetrapods and fishes. Palaeontographica

$803 \quad$ Abteilung A 240:1-27.

804 Klembara, J. 2005. A new discosauriscid seymouriamorph tetrapod from the Lower Permian of

805 Moravia, Czech Republic. Acta Palaeontologica Polonica 50:25-48.

806 Klembara, J. 2009. The skeletal anatomy and relationships of a new discosauriscid

807 seymouriamorph from the Lower Permian of Moravia (Czech Republic). Annals of

$808 \quad$ Carnegie Museum 77:451-483.

809 Klembara, J. 2011. The cranial anatomy, ontogeny, and relationships of Karpinskiosaurus

810 secundus (Amalitzky) (Seymouriamorpha, Karpinskiosauridae) from the Upper Permian of

811 European Russia. Zoological Journal of the Linnean Society 161:184-212.

812 Klembara, J., and Bartík, I. 2000 (for 1999). The postcranial skeleton of Discosauriscus Kuhn, a

813 seymouriamorph tetrapod from the Lower Permian of the Boskovice Furrow (Czech

814 Republic). Transactions of the Royal Society of Edinburgh: Earth Sciences 90:287-316. 
815 Klembara, J., \& Ruta, M. 2004. The seymouriamorph tetrapod Utegenia shpinari from the

816 ?Upper Carboniferous-Lower Permian of Kazakhstan. Part II: Postcranial anatomy and 817 relationships. Transactions of the Royal Society of Edinburgh: Earth Sciences 94:75-93.

818 Klembara, J., Berman, D. S., Henrici, A. C., Ĉerňanský, A., and Werneburg, R. 2006.

819 Comparison of cranial anatomy and proportions of similarly sized Seymouria sanjuanensis $820 \quad$ and Discosauriscus austriacus. Annals of Carnegie Museum 75: 37-49.

821 Klembara, J., Martens, T., \& Bartík, I. 2001. The postcranial remains of a juvenile 822 seymouriamorph tetrapod from the Lower Permian Rotliegend of the Tambach Formation 823 of central Germany. Journal of Vertebrate Paleontology 21:521-527.

824 Konietzko-Meier, D. and Klein, N. 2013. Unique growth pattern of Metoposaurus diagnosticus 825 krasiejowensis (Amphibia, Temnospondyli) from the Upper Triassic of Krasiejów, 826 Poland. Palaeogeography, Palaeoclimatology, Palaeoecology 370:145-157.

827 Konietzko-Meier, D. and Sander, P. M. 2013. Long bone histology of Metoposaurus 828 diagnosticus (Temnospondyli) from the Late Triassic of Krasiejów (Poland) and its 829 paleobiological implications. Journal of Vertebrate Paleontology 33:1003-1018.

830 Konietzko-Meier, D., Danto, M. and Gądek, K. 2014. The microstructural variability of the 831 intercentra among temnospondyl amphibians. Biological Journal of the Linnean $832 \quad$ Society 112:747-764.

833 Konietzko-Meier, D., Shelton, C. D. and Sander, P. M. 2016. The discrepancy between 834 morphological and microanatomical patterns of anamniotic stegocephalian postcrania from 835 the Early Permian Briar Creek Bonebed (Texas). Comptes Rendus Palevol 15:103-114. 
836 Kriloff, A., Germain, D., Canoville, A., Vincent, P., Sache, M., and Laurin, M. 2008. Evolution

837 of bone microanatomy of the tetrapod tibia and its use in palaeobiological inference.

$838 \quad$ Journal of Evolutionary Biology 21:807-826.

839 Laurin, M. 1996a. A reappraisal of Utegenia, a Permo-Carboniferous seymouriamorph

840 (Tetrapoda: Batrachosauria) from Kazakhstan. Journal of Vertebrate Paleontology 16:374-

841383.

842 Laurin, M. 1996b. A reevaluation of Ariekanerpeton, a Lower Permian seymouriamorph

843 (Vertebrata: Seymouriamorpha) from Tadzhikistan. Journal of Vertebrate Paleontology

$844 \quad 16: 653-665$.

845 Laurin, M., Canoville, A., and Germain, D. 2011. Bone microanatomy and lifestyle: a descriptive $846 \quad$ approach. Comptes Rendus Palevol 10:381-402.

847 MacDougall, M. J., Tabor, N. J., Woodhead, J., Daoust, A. R. and Reisz, R. R. 2017. The unique 848 preservational environment of the Early Permian (Cisuralian) fossiliferous cave deposits of 849 the Richards Spur locality, Oklahoma. Palaeogeography, Palaeoclimatology, $850 \quad$ Palaeoecology 475:1-11.

851 Malakhov, D. V. 2000. The topography of the lateral line organs on the skull of Utegenia 852 shpinari. Biota 1:21-26.

853 Marchetti, L., Mujal, E., and Bernardi, M. 2017. An unusual Amphisauropus trackway and its 854 implication for understanding seymouriamorph locomotion. Lethaia 50:162-174.

855 Mays, C., Bevitt, J., and Stilwell, J. 2017. Pushing the limits of neutron tomography in 856 palaeontology: Three-dimensional modelling of in situ resin within fossil plants. 857 Palaeontologia Electronica 20:Art. No. 3.57A. 
858 McHugh, J. B. 2014. Paleohistology and histovariability of the Permian stereospondyl

$859 \quad$ Rhinesuchus. Journal of Vertebrate Paleontology 34:59-68.

860 McHugh, J. B. 2015. Paleohistology of Micropholis stowi (Dissorophoidea) and Lydekkerina

861 huxleyi (Lydekkerinidae) humeri from the Karoo Basin of South Africa, and implications

862 for bone microstructure evolution in temnospondyl amphibians. Journal of Vertebrate

$863 \quad$ Paleontology 35:e902845.

864 Moodie, R. L. 1908. The lateral line system in extinct Amphibia. Journal of Morphology 19:511$865 \quad 540$.

866 O'Leary, M. A., and Kaufman, S. G. 2012. MorphoBank 3.0: Web application for morphological 867 phylogenetics and taxonomy.

868 Olson, E. C. 1976. The exploitation of land by early tetrapods. In: d'A. Bellairs A and Cox CB, 869 eds. Morphology and Biology of Reptiles. Linnean Society Symposium Series No. 3.

870 London: Academic Press, 1-30.

871 Padian, K., and Lamm, E. T. eds. 2013. Bone histology of fossil tetrapods: advancing methods, 872 analysis, and interpretation. Berkeley: University of California Press.

873 Pawley, K., and Warren, A. 2005. A terrestrial stereospondyl from the Lower Triassic of South 874 Africa: the postcranial skeleton of Lydekkerina huxleyi (Amphibia:

875 Temnospondyli). Palaeontology, 48:281-298.

876 Peabody, F. E. 1961. Annual growth zones in living and fossil vertebrates. Journal of $877 \quad$ Morphology 108:11-62.

878 Quemeneur, S., de Buffrénil, V., \& Laurin, M. 2013. Microanatomy of the amniote femur and 879 inference of lifestyle in limbed vertebrates. Biological Journal of the Linnean Society $880 \quad 109: 644-655$. 
881 Richards, E. J. 2016. The Ontogenetic Osteohistology of the Eureptile Captorhinus aguti 882 (Reptilia: Captorhinidae) and the Community Histology of the Early Permian Fissure-Fill 883 Fauna Dolese Quarry, Richards Spur, Oklahoma. Unpublished M.Sc. thesis, University of $884 \quad$ Toronto.

885 Rockwell, H., Evans, F. G. and Pheasant, H. C. 1938. The comparative morphology of the 886 vertebrate spinal column. Its form as related to function. Journal of Morphology 63:87887 117.

Romer, A. S. 1956. Osteology of the Reptiles. Chicago: Chicago University Press.

889 Rozenblut, B., and Ogielska, M. 2005. Development and growth of long bones in European water frogs (Amphibia: Anura: Ranidae), with remarks on age determination. Journal of Morphology 265:.304-317.

892 Sanchez, S. and Schoch, R. R. 2013. Bone histology reveals a high environmental and metabolic plasticity as a successful evolutionary strategy in a long-lived homeostatic Triassic temnospondyl. Evolutionary Biology 40:627-647.

Sanchez, S., Klembara, J., Castanet, J., and Steyer, J. S. 2008. Salamander-like development in a 896 seymouriamorph revealed by palaeohistology. Biology Letters 4:411-414. bone microstructural organization in Apateon: histological evidence of paedomorphic conditions in branchiosaurs. Evolution \& Development 12:315-328.

Sanchez, S., Germain, D., de Ricqlès, A., Abourachid, A., Goussard, F. and Tafforeau, P. $2010 \mathrm{~b}$. 901 Limb-bone histology of temnospondyls: implications for understanding the diversification

902 of palaeoecologies and patterns of locomotion of Permo-Triassic tetrapods. Journal of 903 Evolutionary Biology 23:2076-2090. 
904 Schoch, R. R. 2002. The evolution of metamorphosis in temnospondyls. Lethaia 35:309-327.

905 Schoch, R. R., and Rubidge, B. S. 2005. The amphibamid Micropholis from the Lystrosaurus

906 assemblage zone of South Africa. Journal of Vertebrate Paleontology 25:502-522.

907 Schroeder, E. E., and Baskett, T.S. 1968. Age estimation, growth rates, and population structure 908 in Missouri bullfrogs. Copeia 1968:583-592.

909 Steyer, J. S., Laurin, M., Castanet, J. and de Ricqlès, A. 2004. First histological and

910 skeletochronological data on temnospondyl growth: palaeoecological and

911 palaeoclimatological implications. Palaeogeography, Palaeoclimatology,

912 Palaeoecology 206:193-201.

913 Sullivan, C. and Reisz, R. R. 1999. First record of Seymouria (Vertebrata: Seymouriamorpha)

914 from Early Permian fissure fills at Richards Spur, Oklahoma. Canadian Journal of Earth

$915 \quad$ Sciences 36:1257-1266.

916 Sumida, S. S., Lombard, R. E., and Berman, D. S. 1992. Morphology of the atlas-axis complex

917 of the late Palaeozoic tetrapod suborders Diadectomorpha and Seymouriamorpha.

$918 \quad$ Philosophical Transactions of the Royal Society of London B: Biological Sciences 336:

$919 \quad 259-273$.

920 Tsiora, A., and Kyriakopoulou-Sklavounou, P. 2002. A skeletochronological study of age and 921 growth in relation to adult size in the water frog Rana epeirotica. Zoology 105:55-60.

922 Vaughn, P. P. 1966. Seymouria from the Lower Permian of southeastern Utah, and possible 923 sexual dimorphism in that genus. Journal of Paleontology 40:603-612.

924 Watson, D. M. S. 1918. On Seymouria, the most primitive known reptile. Proceedings of the $925 \quad$ Zoological Society of London 88:267-301. 
926 Williston, S. W. 1911. Restoration of Seymouria baylorensis Broili, an American cotylosaur. The 927 Journal of Geology 19:232-237.

928 Witzmann, F. 2016. CO 2-metabolism in early tetrapods revisited: inferences from osteological 929 correlates of gills, skin and lung ventilation in the fossil record. Lethaia 49:492-506. 


\section{Figure 1}

Posterior presacral vertebrae of Seymouria.

A, OMNH 79346 in anterior view; B, the same in posterior view; C, the same in dorsal view;

D, the same in ventral view; $\mathbf{E}$, the same in left lateral view; $\mathbf{F}$, OMNH 79349 in anterior view;

$\mathbf{G}$, the same in posterior view; $\mathbf{H}$, the same in dorsal view; $\mathbf{I}$, the same in ventral view; $\mathbf{J}$, the same in left lateral view; K, OMNH 79350 in anterior view; L, the same in posterior view; $\mathbf{M}$, the same in dorsal view; $\mathbf{N}$, the same in ventral view; $\mathbf{0}$, the same in left lateral view; $\mathbf{P}$, OMNH 79353 in anterior view; Q, the same in posterior view; $\mathbf{R}$, the same in dorsal view; $\mathbf{S}$, the same in ventral view; $\mathbf{T}$, the same in left lateral view; U, ROMVP 81198 in anterior view; $\mathbf{V}$, the same in posterior view; $\mathbf{W}$, the same in dorsal view; $\mathbf{X}$, the same in ventral view; $\mathbf{Y}$, the same in left lateral view; Z, ROMVP 81199 in anterior view; AA, the same in posterior view; BB, the same in dorsal view; CC, the same in ventral view; DD, the same in left lateral view. Scale bar equals $1 \mathrm{~cm}$. $\mathbf{n}$, notochordal canal; nc, neural canal; poz, postzygapophysis; prz, prezygapophysis; snc, supraneural canal 

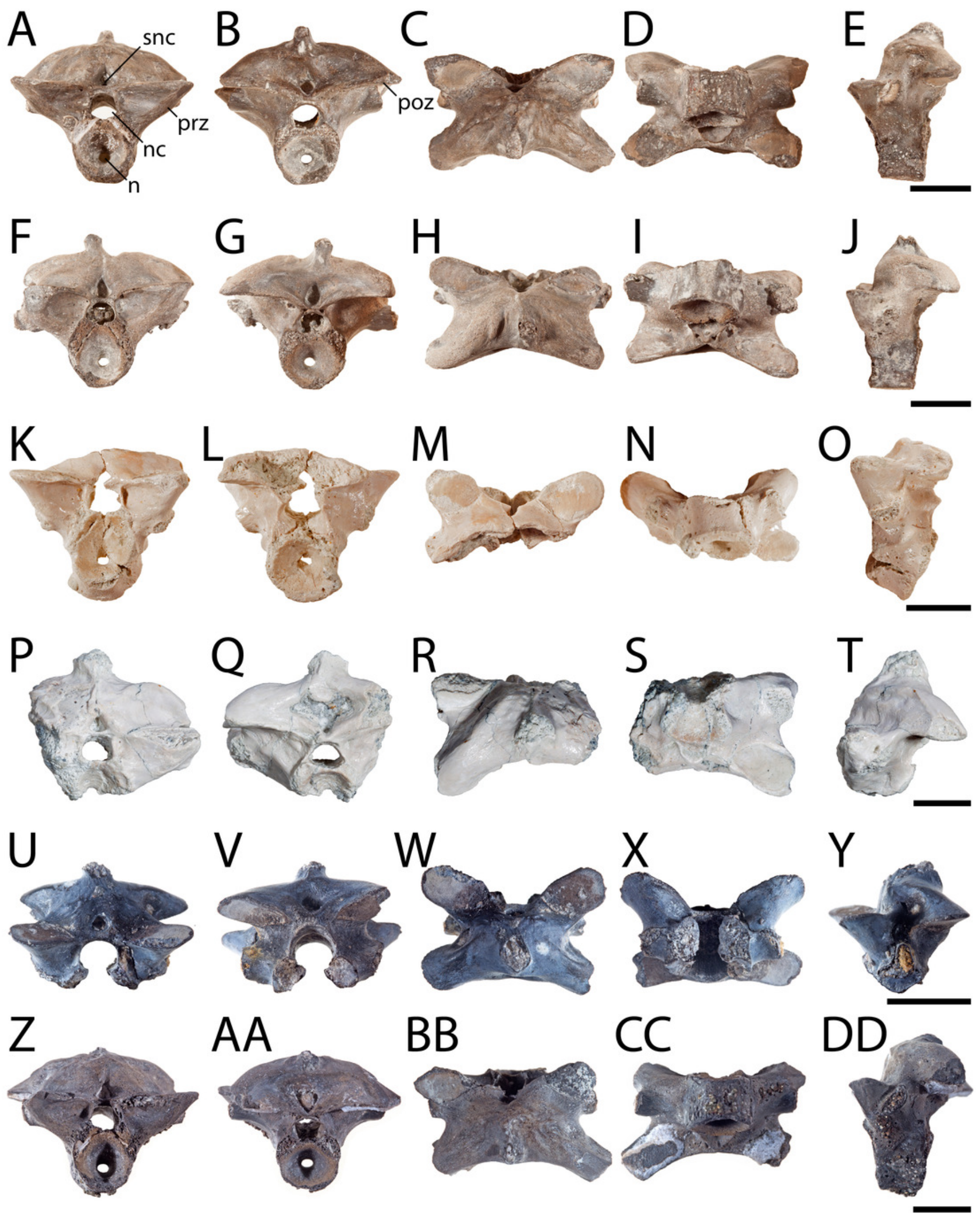


\section{Figure 2}

Anterior presacral vertebrae of Seymouria.

A, OMNH 79351 in anterior view; B, the same in posterior view; $\mathbf{C}$, the same in dorsal view;

D, the same in ventral view; E, the same in left lateral view; F, OMNH 79352 in anterior view;

$\mathbf{G}$, the same in posterior view; $\mathbf{H}$, the same in dorsal view; $\mathbf{I}$, the same in ventral view; J, the same in left lateral view. Scale bar equals $1 \mathrm{~cm}$. dp, diapophysis; $\mathbf{n}$, notochordal canal; nc, neural canal; poz, postzygapophysis; prz, prezygapophysis; snc, supraneural canal
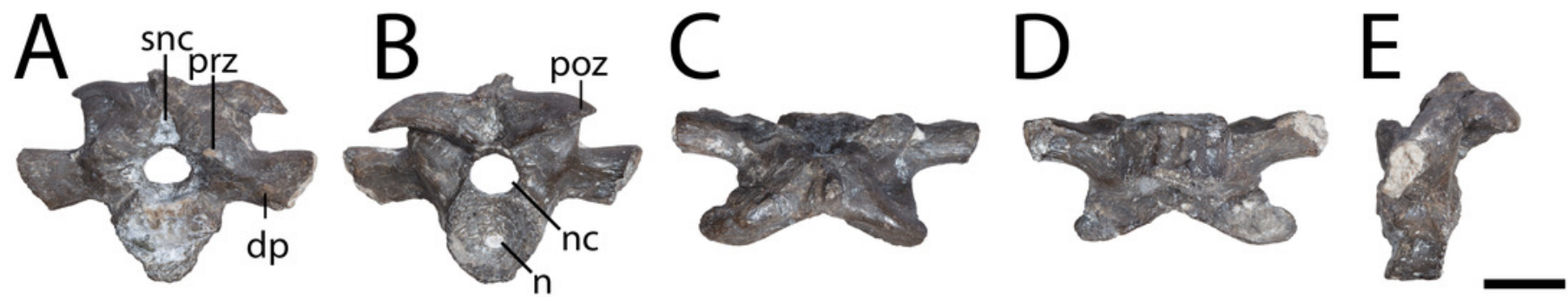

5

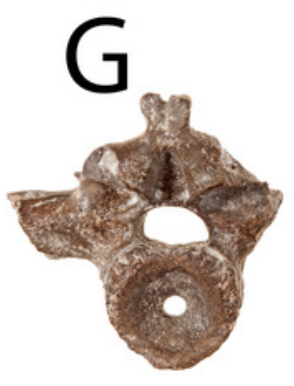

$\square$

$\mathrm{J}$
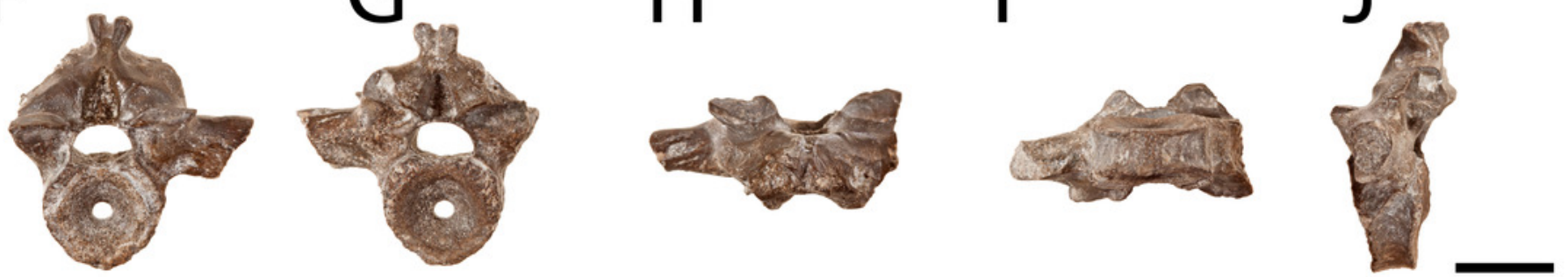
Figure 3

Articulated vertebrae of Seymouria.

A, OMNH 79347 in dorsal view; B, OMNH 79348 in dorsal view; C, the same in ventral view;

D, the same in left lateral view; E, the same in right lateral view. Scale bar equals $1 \mathrm{~cm}$. poz, postzygapophysis; prz, prezygapophysis 


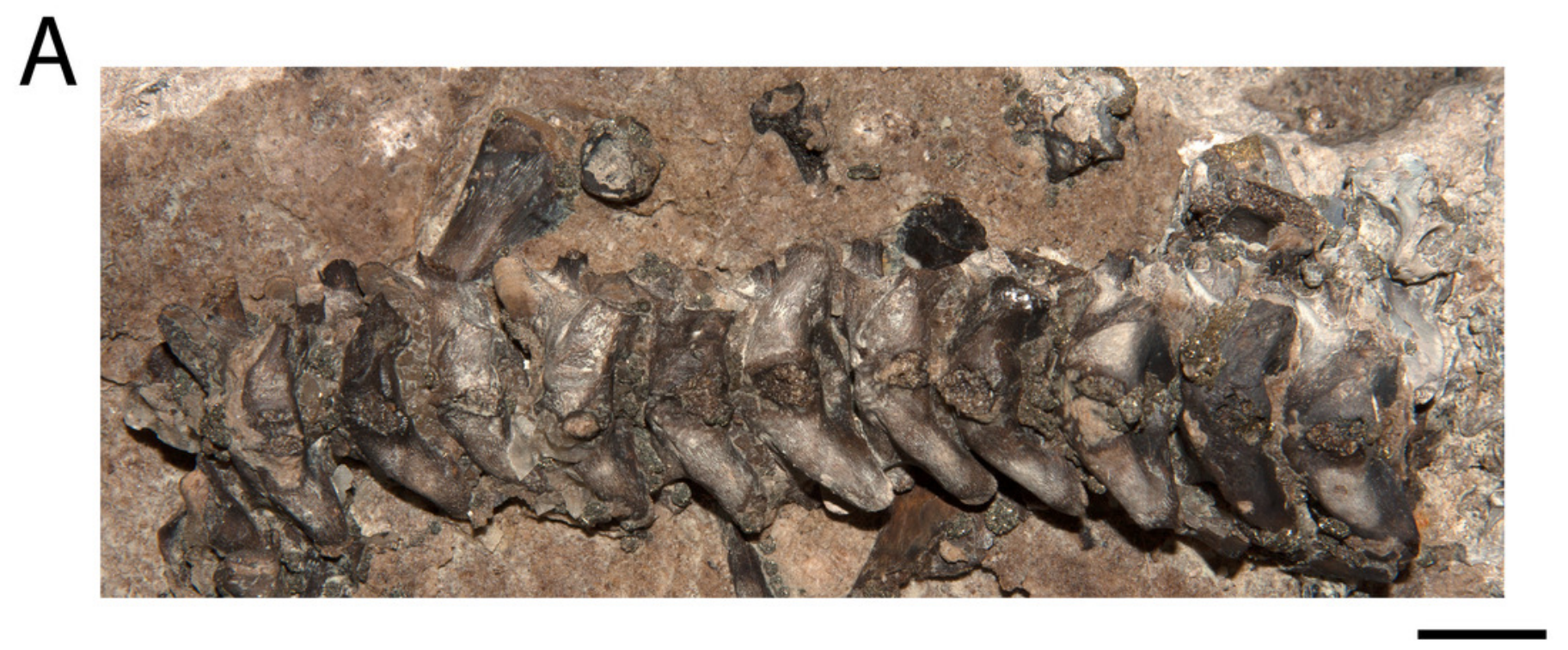

B

D
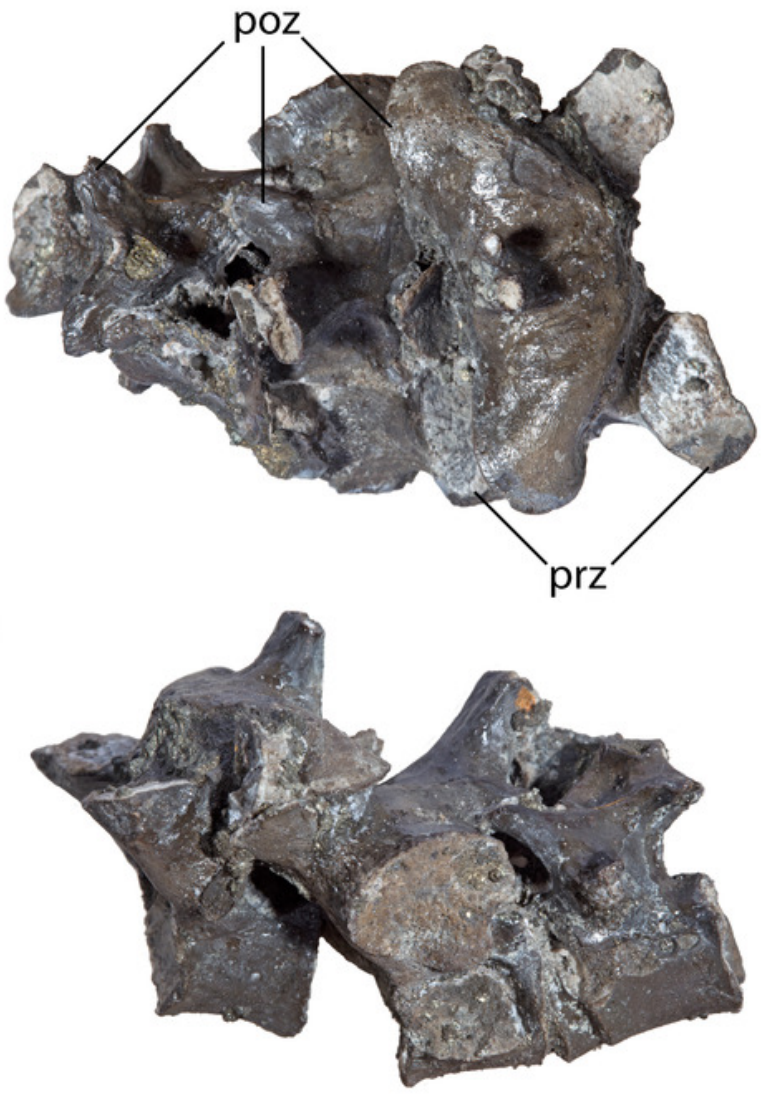
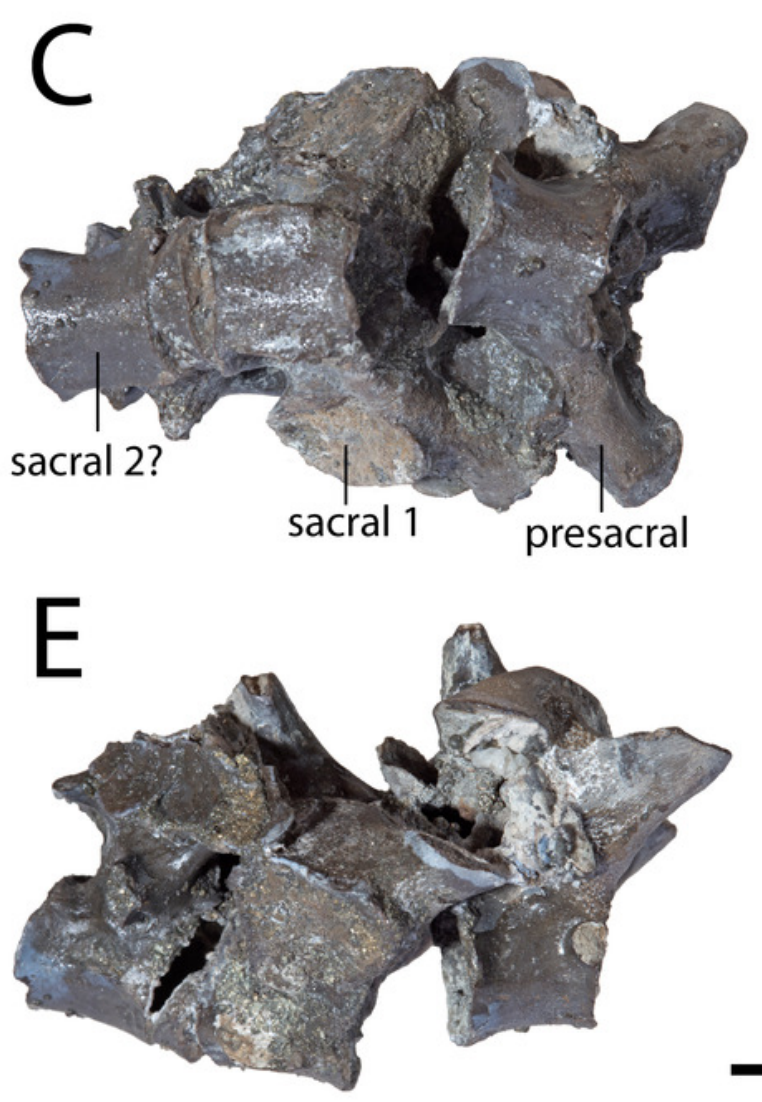
Figure 4

\section{OMNH 74721.}

A, anterior view, B, posterior view, C, dorsal view, D, ventralview, E, proximal view, and F, distal view. Scale bar equals $1 \mathrm{~cm}$. cap, capitellum; dpc, deltopectoral crest; ect, ectepicondyle; ent, entepicondyle; entf, entepicondylar foramen; entr, entepicondylar ridge; sbcsc, supcoracoscapularis; sup, supinator process 

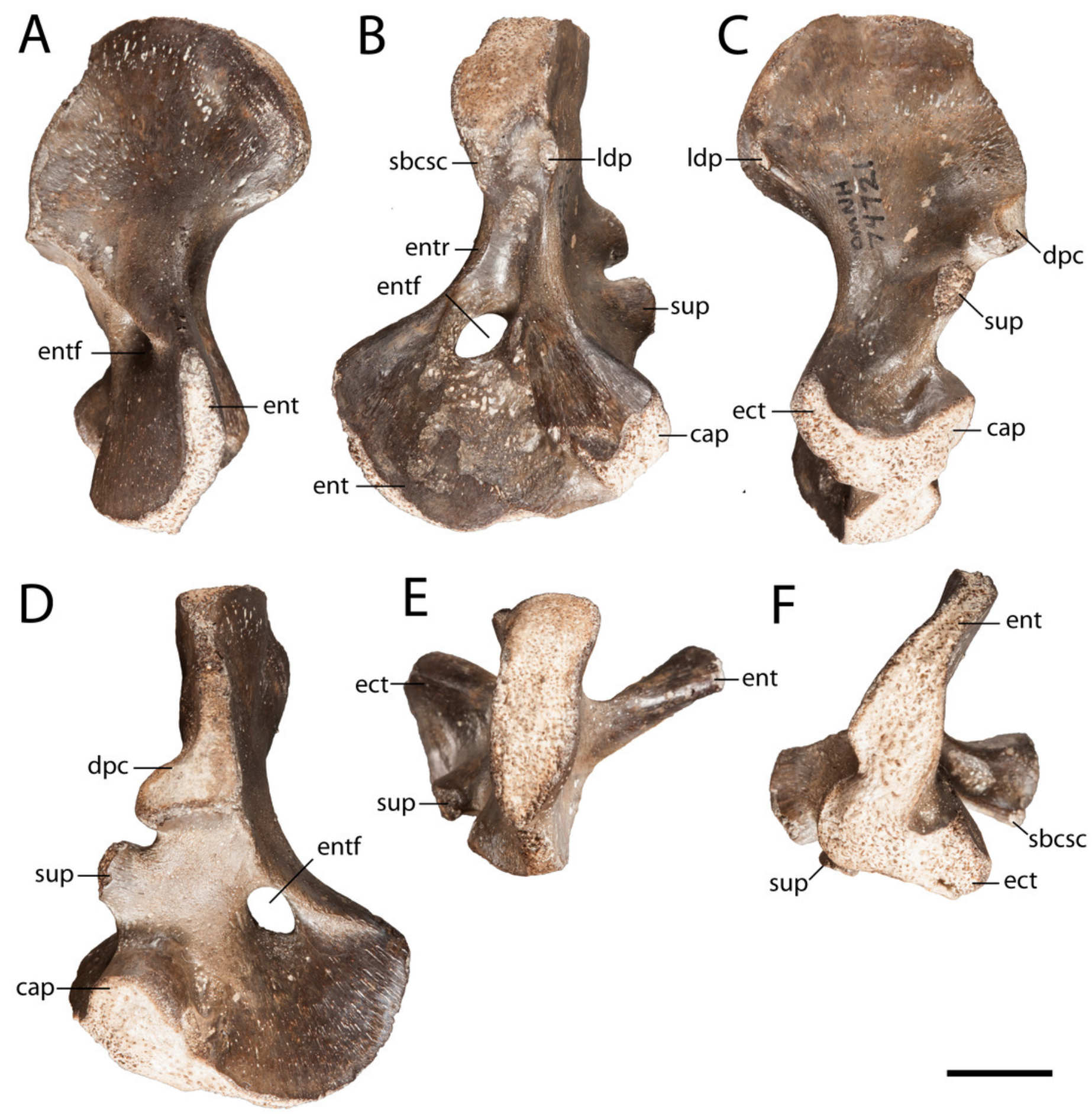


\section{Figure 5}

Hindlimb elements of Seymouria.

A, photograph of ROMVP 80915 and ROMVP 80917 in posterior view; B, the same in ventral view; C, digital rendering of ROMVP 80916 in posterior view; D, the same in anterior view; $\mathbf{E}$, the same in dorsal view; $\mathbf{F}$, the same in ventral view; $\mathbf{G}$, the same in proximal view; $\mathbf{H}$, the same in distal view. Scale bar equals $1 \mathrm{~cm}$. adc, adductor crest; fibc, fibular condyle; icf, intercondylar fossa; itf, intertrochanteric fossa; pfm, m. puboischiofemoralis; tibc, tibial condyle; tr, trochanter 

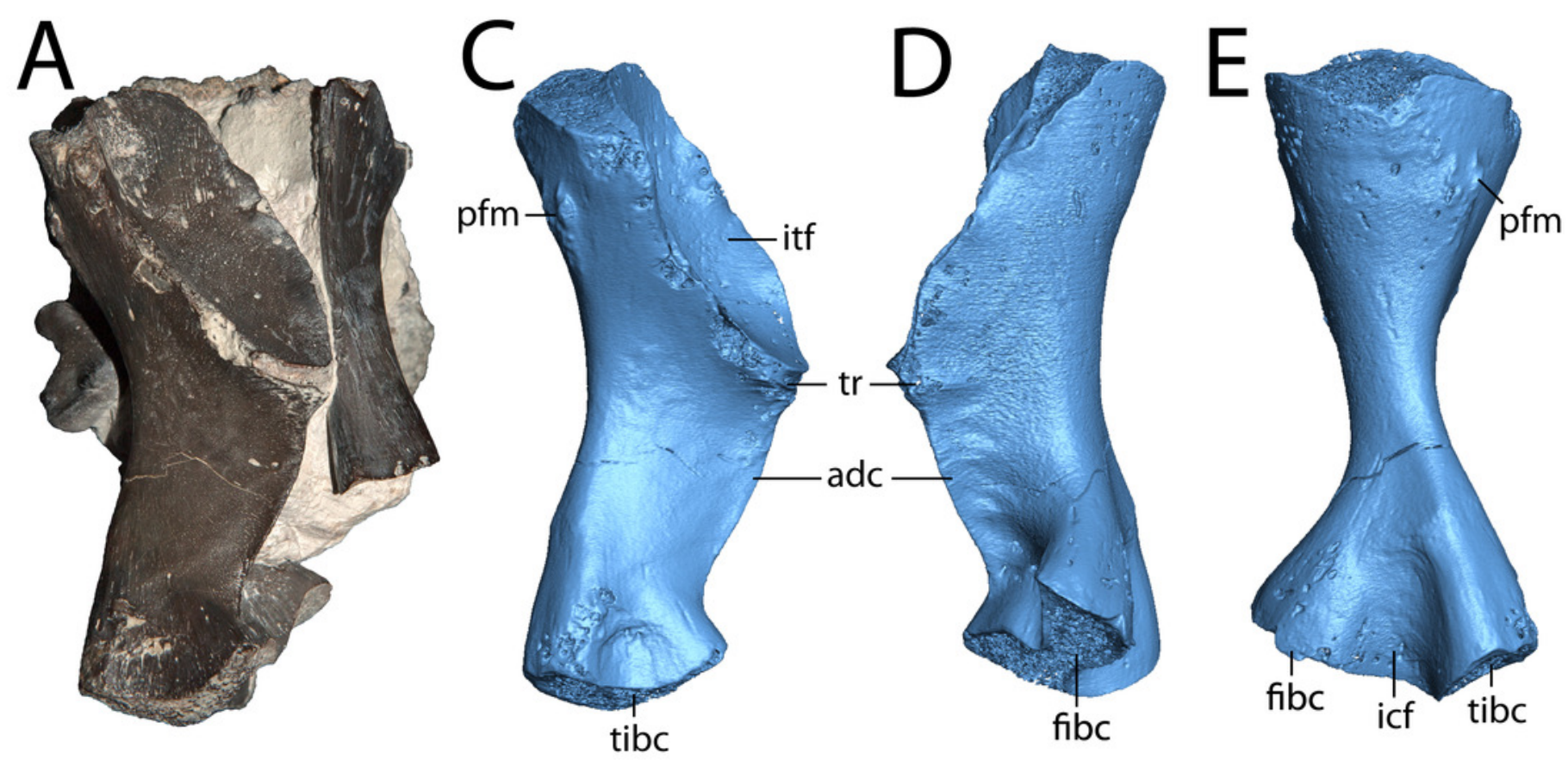

B

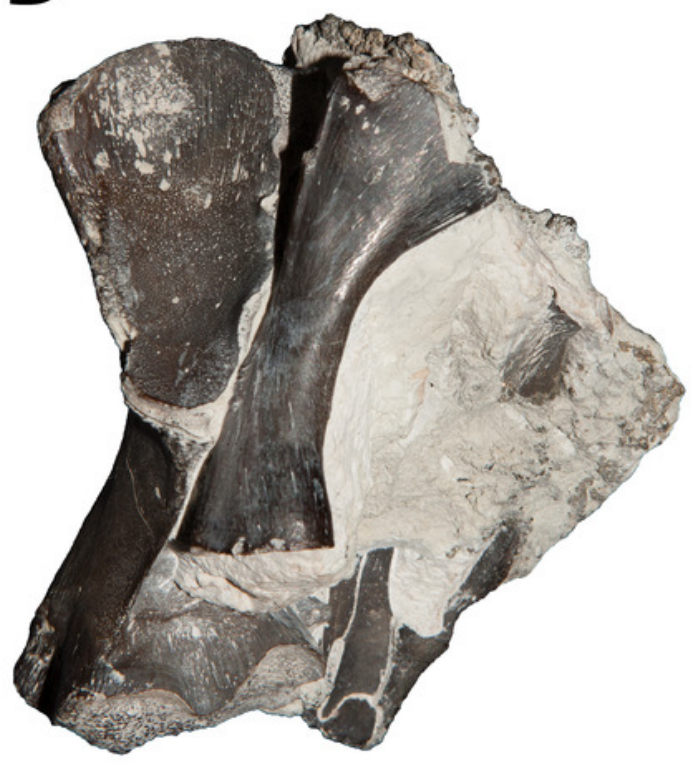

$\mathrm{F}$

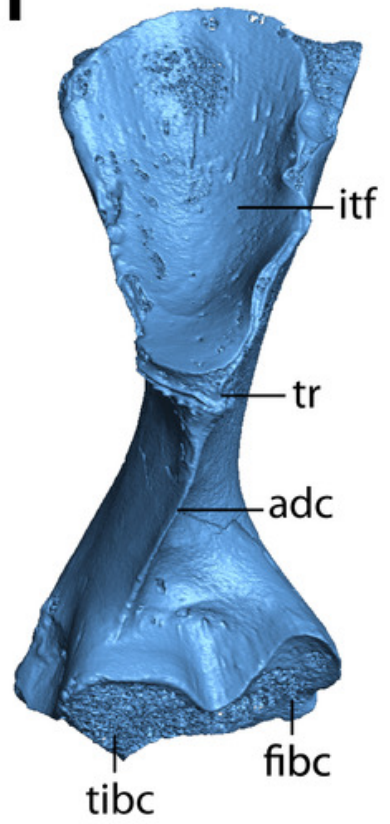

G

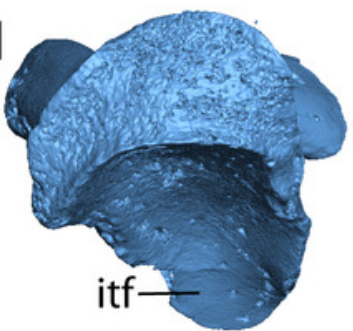

$\mathrm{H}$

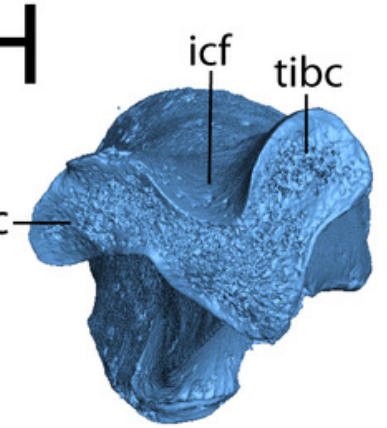


Figure 6

Partial femora of Seymouria.

A-F, ROMVP 80916 and G-L, ROMVP 81200 in anterior, posterior, dorsal, ventral, proximal, and distal views. Scale bar equals $1 \mathrm{~cm}$. 
A

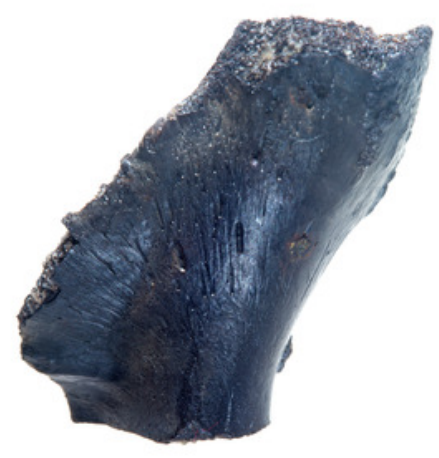

D

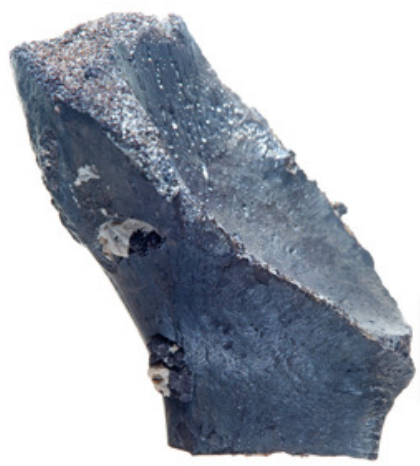

G

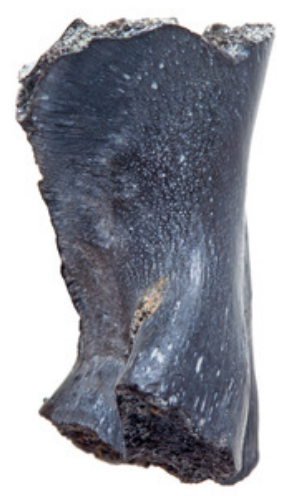

J

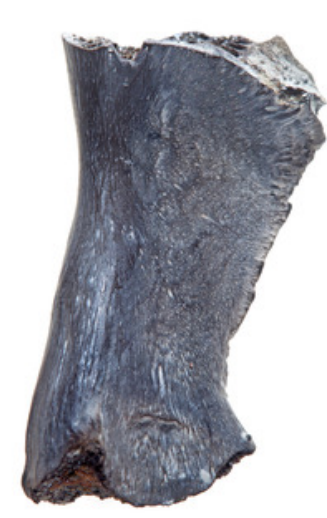

B

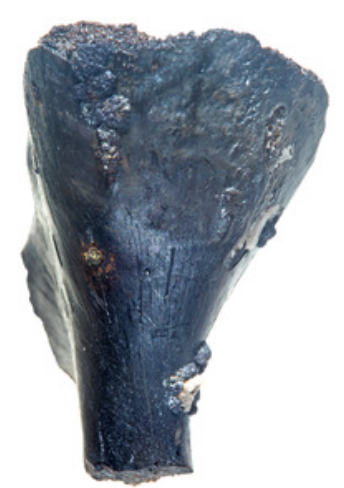

$\mathrm{E}$

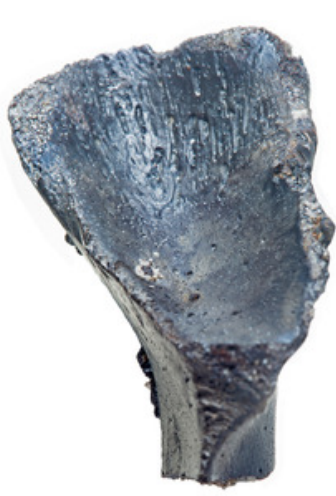

$\mathrm{H}$

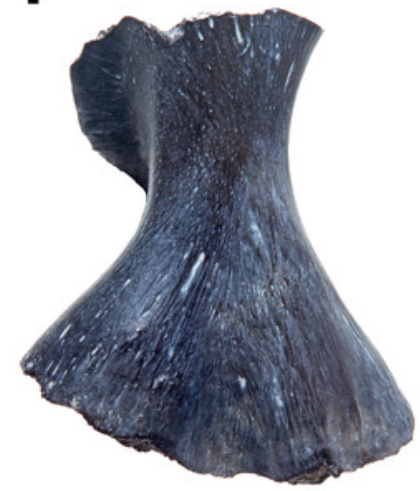

$\mathrm{K}$

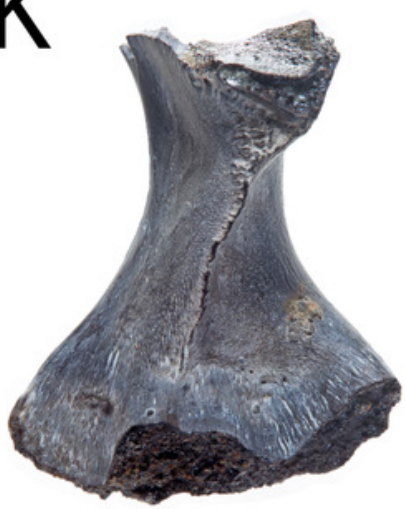

C

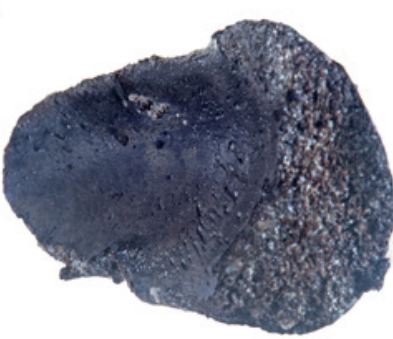

$\mathrm{F}$

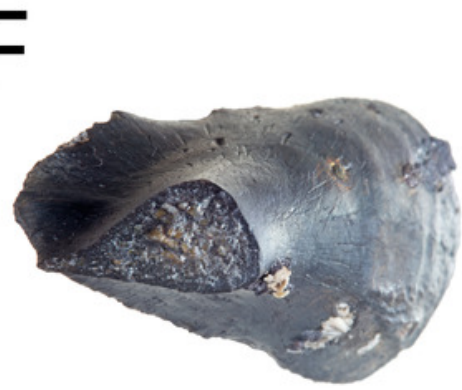

I

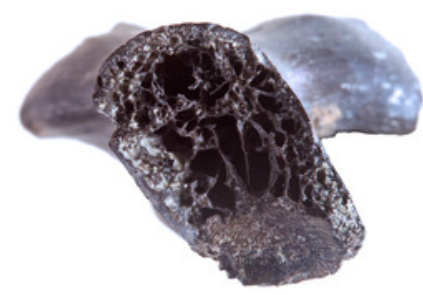

$\mathrm{L}$

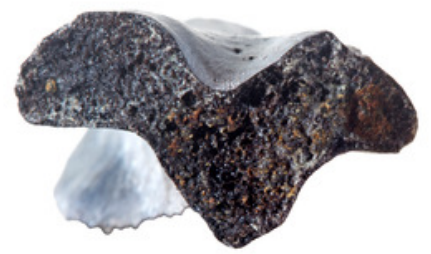




\section{Figure 7}

Digital renderings of ROMVP 80917.

A, anterior; B, posterior; C, medial; D, lateral; E, proximal; F, distal views. Scale bar equals 1 $\mathrm{cm}$. ifm, m. iliofibularis

A

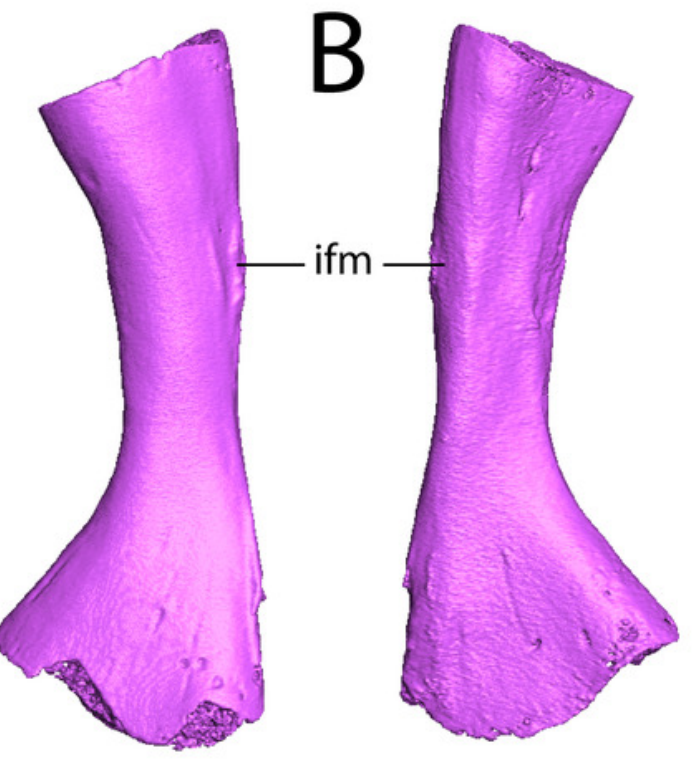

C

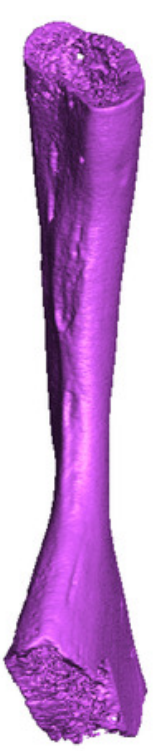

$\mathrm{D}$

ifm
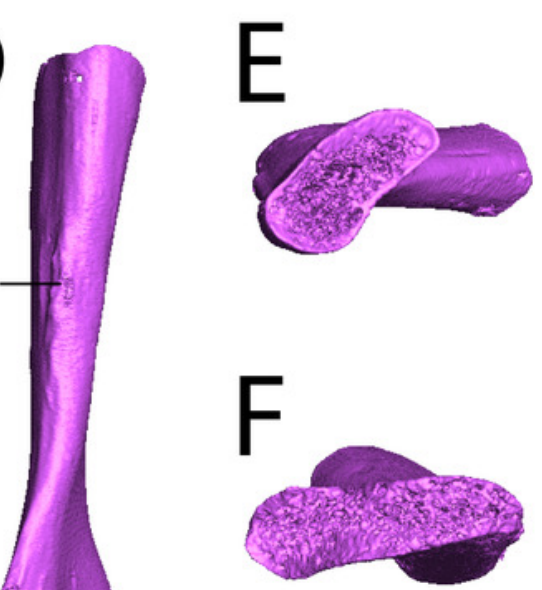


\section{Figure 8}

Histological sections of a presacral vertebra (ROMVP 81199) of Seymouria.

A, Full sagittal section; B, close-up under cross-polarized light of the ventral border of the neural arch showing remodelling; $\mathbf{C}$, close-up under cross-polarized light of the thickened posterior surface; D, half transverse section; E, close-up under cross-polarized light of the dorsal surface; F, close-up under cross-polarized light of the cartilaginous separation between the neural arch and the centrum. Scale bars equal to $1 \mathrm{~mm}$ (A, D); $250 \mu \mathrm{m}$ (B-C, EF). $\mathbf{n}$, notochordal canal; na, neural arch; nc, neural canal; ns, neural spine; $\mathbf{p}$, pleurocentrum; snc, supraneural canal 


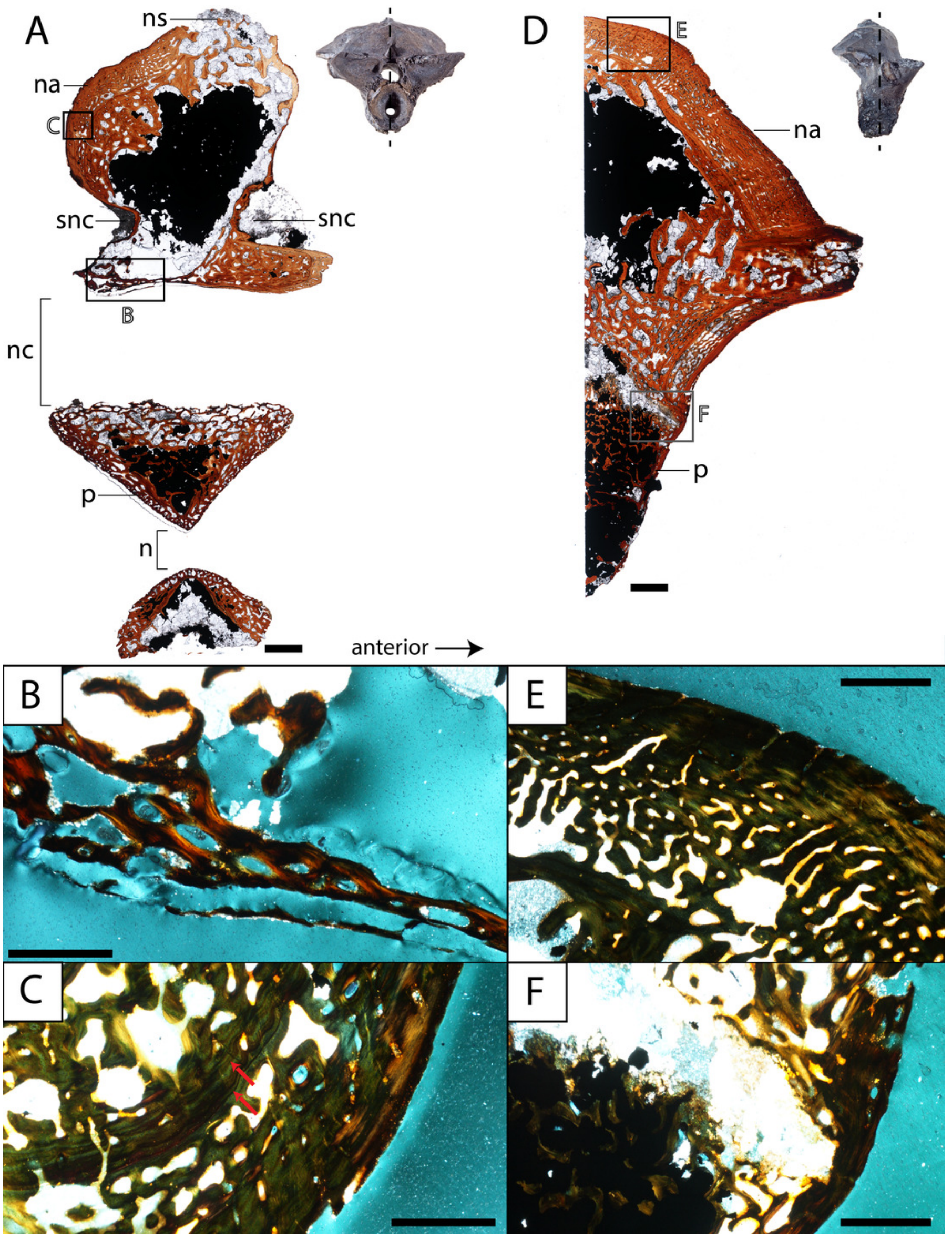


Figure 9

Histological sections of a presacral vertebra (ROMVP 81198) of Seymouria.

A, Full sagittal section; B, close-up under cross-polarized light of the ventral border of the neural arch showing remodelling; $\mathbf{C}$, close-up under cross-polarized light of the thickened posterior surface; D, half transverse section; E, close-up under cross-polarized light of the dorsal surface; $\mathbf{F}$, close-up under cross-polarized light of the geometric center of the neural arch. Scale bars equal to $1 \mathrm{~mm}$ (A, D); $250 \mu \mathrm{m}$ (B-C, E-F). na, neural arch; nc, neural canal; ns, neural spine; snc, supraneural canal 

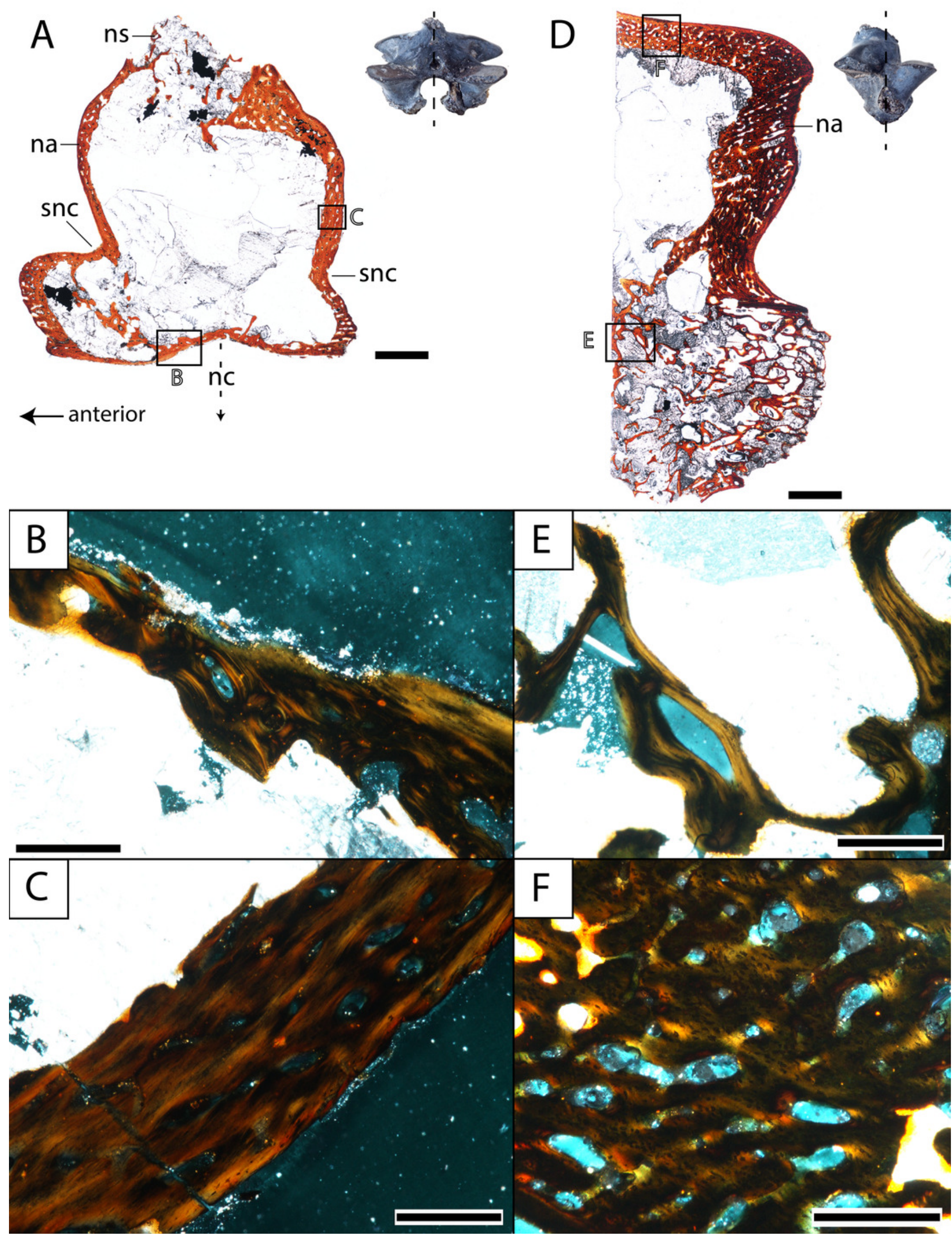

Peer) reviewing PDF | (2019:10:42003:2:0:NEW 30 Jan 2020) 


\section{Figure 10}

Isolated profiles of OMNH 79348.

A, D, G, digital renderings indicating location of digital sections; B-C, sagittal sections of presacral vertebra at mid-centrum (B) and mid-diapophysis (C); E-F, sagittal sections of sacral vertebra at mid-centrum (E) and mid-diapophysis (F); H-G, sagittal sections of caudal vertebra at mid-centrum (H) and mid-diapophysis (I). Scale bar equals $1 \mathrm{~cm}$. $\mathbf{n}$, notochordal canal; nc, neural canal 

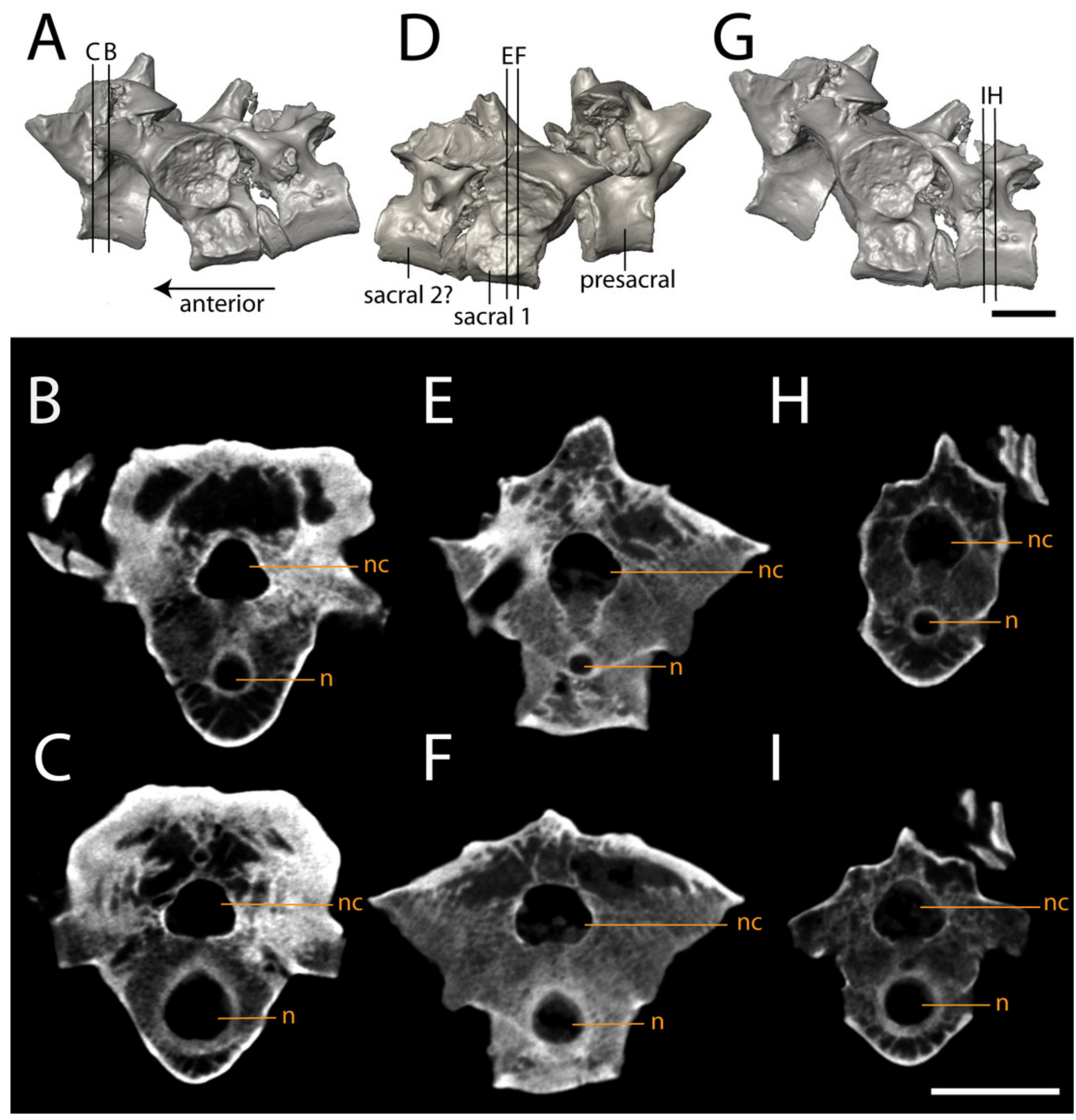


\section{Figure 11}

Histological section of a partial femur (ROMVP 80916) of Seymouria.

A, full cross-section near the minimum diaphyseal circumference; B, close-up of the cortical bone; C, close-up under cross-polarized light of the remodelled bone interface between the cortical bone and the medullary cavity. Note that part $\mathrm{C}$ is from a different thin section than in part $A$ and thus an inset magnification box is not marked. Scale bars equal to $1 \mathrm{~mm}(A)$; $250 \mu \mathrm{m}$ (B-C). a, annulus; gz, growth zone; po, primary osteon; so, secondary osteon; vc, vascular canal. Arrows mark rest lines. 

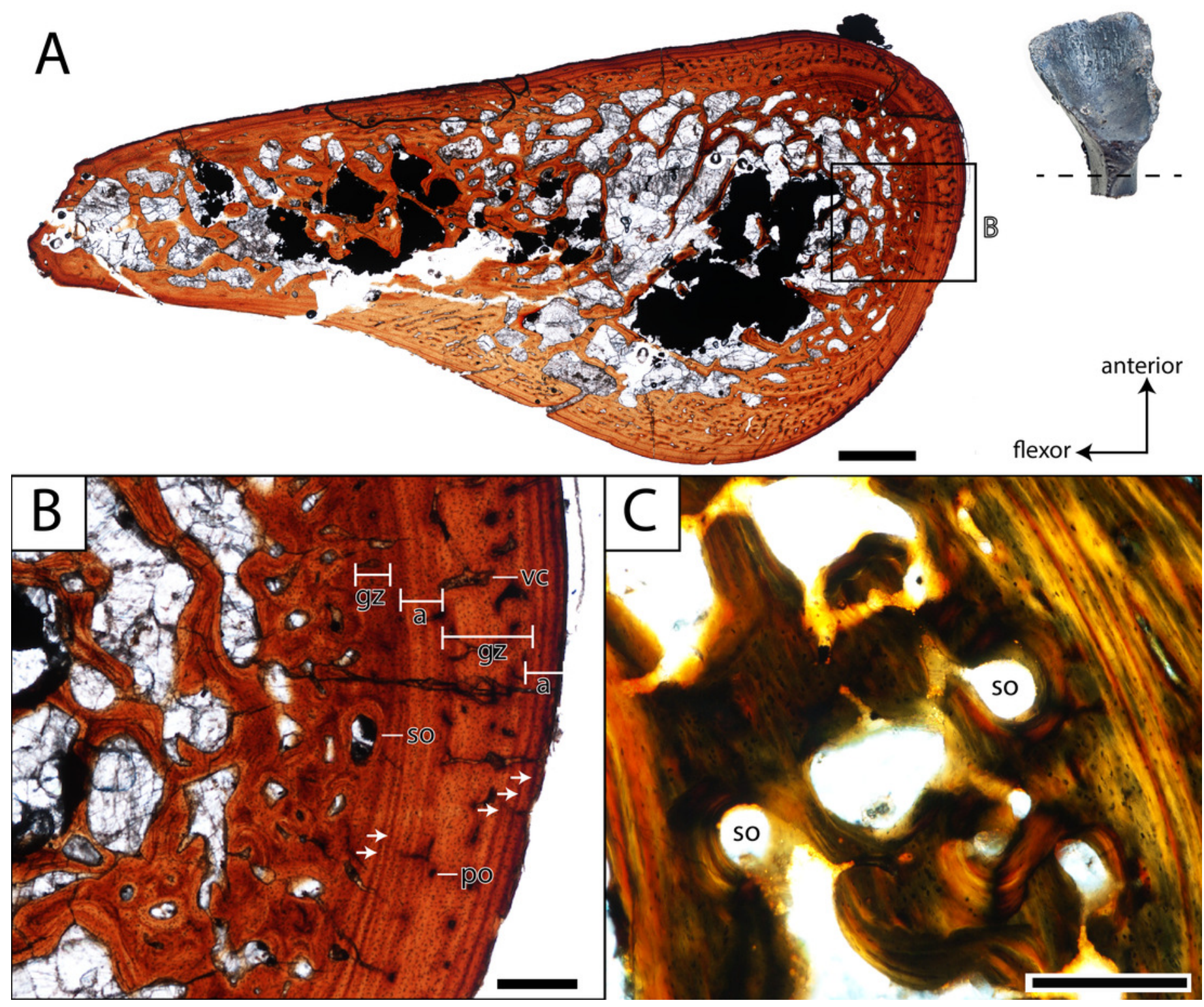


\section{Figure 12}

Histological section of a partial femur (ROMVP 81200) of Seymouria.

A, full cross-section near the minimum diaphyseal circumference; $\mathbf{B}$, close-up of the cortical bone showing four lines of arrested growth (LAGs) marked by black arrows; C, close-up under cross-polarized light of the remodelled bone interface between the cortical bone and the medullary cavity. Scale bars equal to $1 \mathrm{~mm}$ (A); 250 um (B-C). a, annulus; gz, growth zone; po, primary osteon; so, secondary osteon; vc, vascular canal. Arrows mark rest lines. 

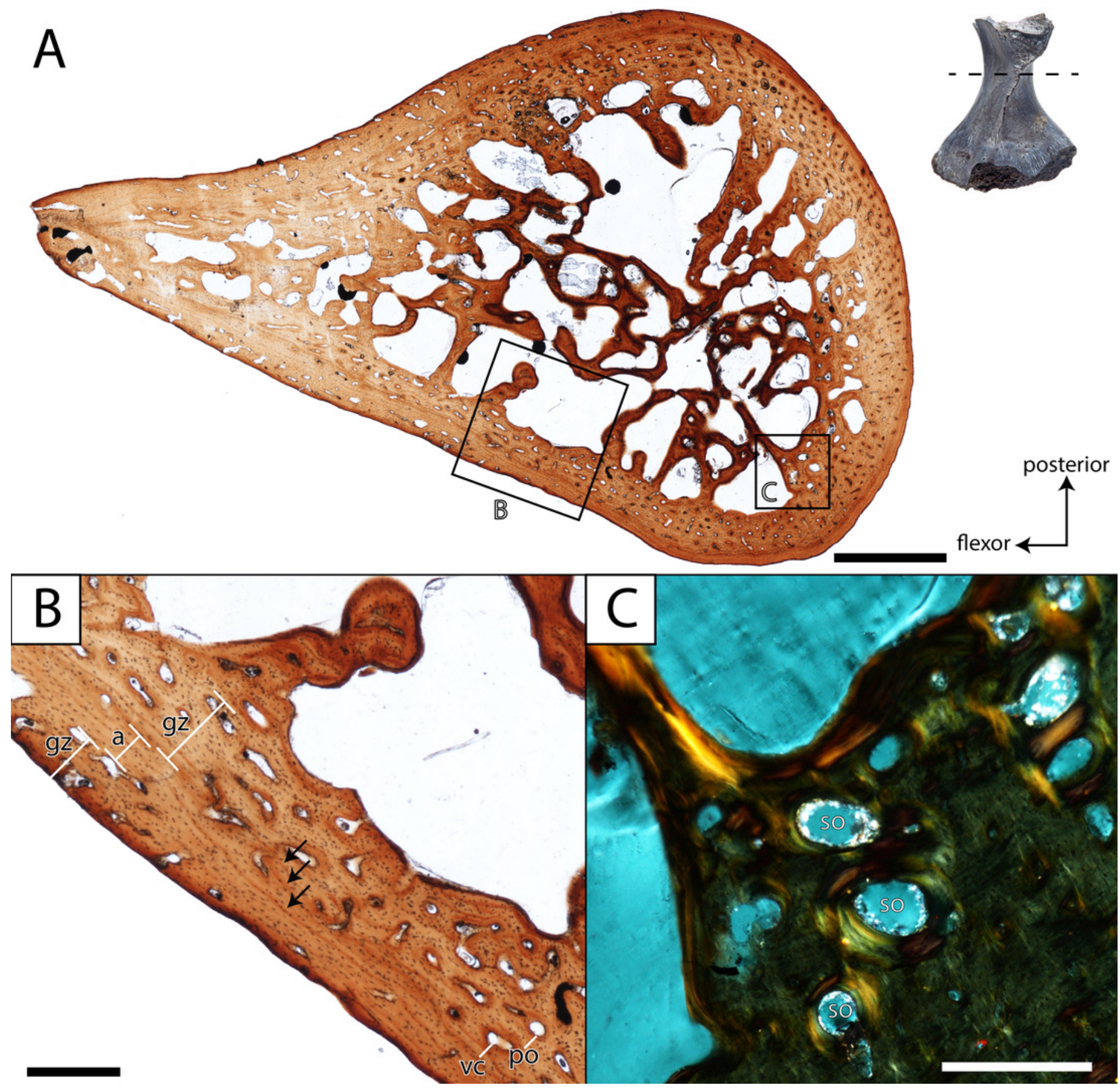


\section{Figure 13}

Digital section of a femur (ROMVP 80915) of Seymouria.

A, digital rendering showing location of section; B, transverse digital section. Scale bar equals $5 \mathrm{~mm}$.
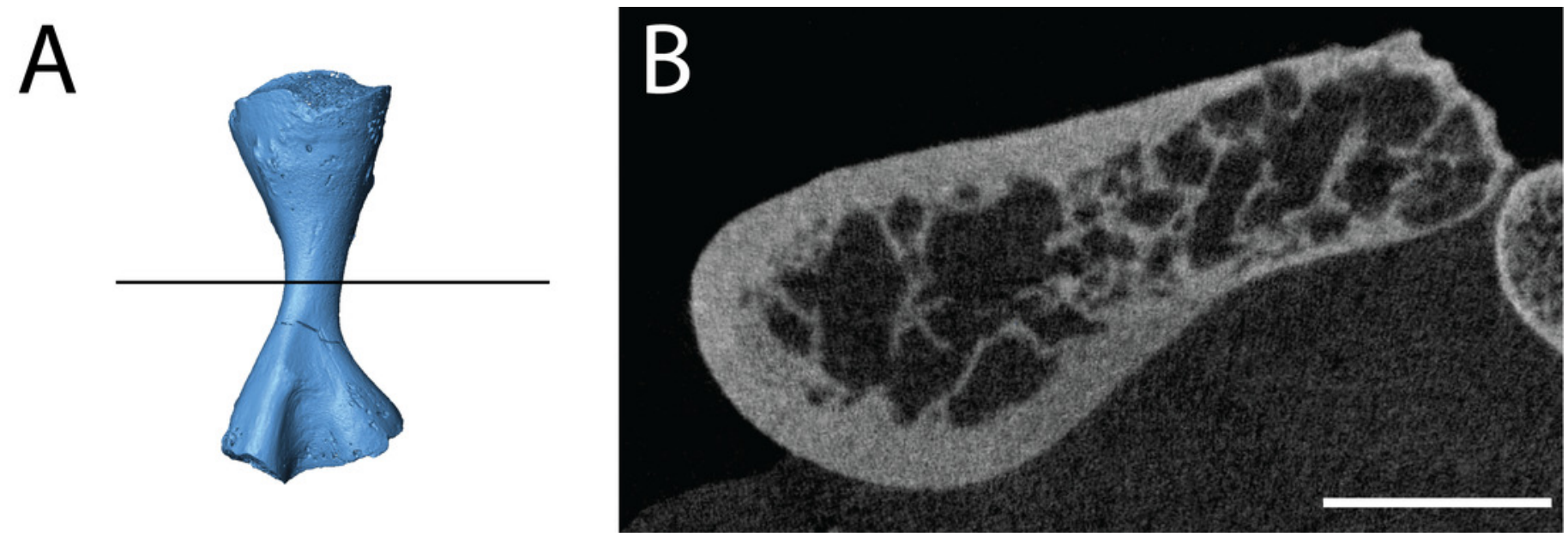


\section{Figure 14}

Conceptual phylogeny adapted from Klembara (2011), illustrating the distribution of aquatic and terrestrial taxa among seymouriamorphs.

Blue boxes represent taxa interpreted as being aquatic. Green boxes represent taxa interpreted as terrestrial. Grey boxes represent taxa for which no interpretation has been made. Boxes in pale blue or green containing question marks indicate taxa for which there have been some suggestions regarding the possible ecology of a given ontogenetic stage, but for which there are no known specimens that definitively verify the suggested interpretations.

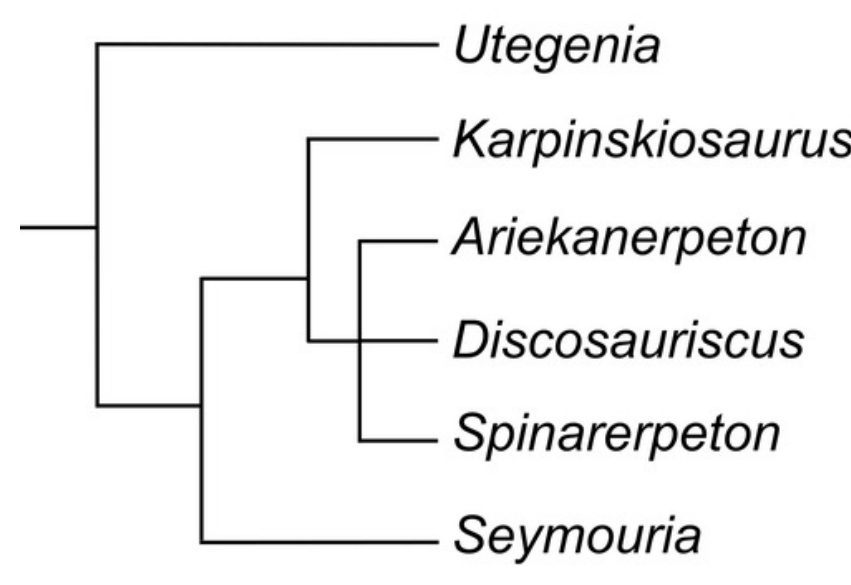

Age Juveniles Adults
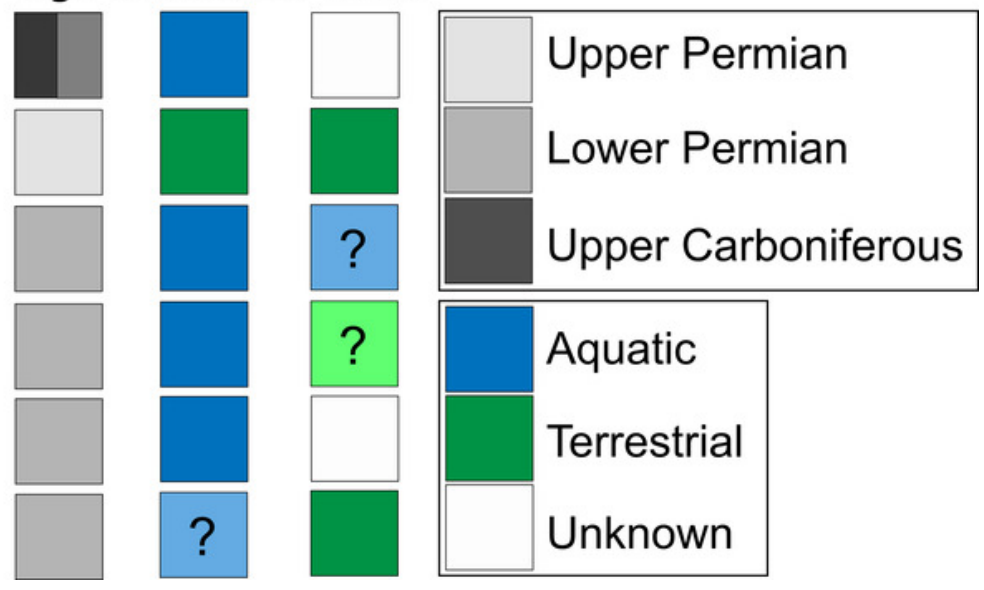